\title{
Glycolytic Inhibition and Calcium Overload as Consequences of Exogenously Generated Free Radicals in Rabbit Hearts
}

\author{
Mary C. Corretti, Yukihiro Koretsune, Hideo Kusuoka, V. P. Chacko, ${ }^{*}$ Jay L. Zweier, and Eduardo Marban \\ Division of Cardiology, Department of Medicine, Department of Radiology,* The Johns Hopkins University \\ School of Medicine, Baltimore, Maryland 21205
}

\begin{abstract}
Free radicals have been implicated in the pathogenesis of reperfusion injury, but it is unclear how they exert their deleterious effects on cellular metabolism. Several lines of indirect evidence suggest that free radicals elevate intracellular $\mathrm{Ca}^{2+}$ concentration $\left(\left[\mathrm{Ca}^{2+}\right]_{1}\right)$ and inhibit glycolysis as part of their mechanism of injury. We tested these ideas directly in hearts subjected to hydroxyl radicals produced by the Fenton and Haber-Weiss reactions. Nuclear magnetic resonance spectra were obtained from Langendorff-perfused rabbit hearts before, during, and after $4 \mathrm{~min}$ of perfusion with $\mathrm{H}_{2} \mathrm{O}_{2}(0.75 \mathrm{mM})$ and $\mathrm{Fe}^{3+}$-chelate (0.1 mM). Isovolumic left ventricular pressure exhibited progressive functional deterioration and contracture after exposure to $\mathrm{H}_{2} \mathrm{O}_{2}+\mathrm{Fe}^{3+}$. Phosphorus nuclear magnetic resonance (NMR) spectra revealed partial ATP depletion and sugar phosphate accumulation indicative of glycolytic inhibition. To measure $\left[\mathrm{Ca}^{2+}\right]_{\text {, }}$, fluorine NMR spectra were acquired in a separate group of hearts loaded with the $\mathrm{Ca}^{2+}$ indicator 5F-BAPTA [5,5'-difluoro derivative of 1,2-bis-(o-aminophenoxy)ethane- $N, N, N^{\prime}, N^{\prime}$-tetraacetic acid]. Mean time-averaged

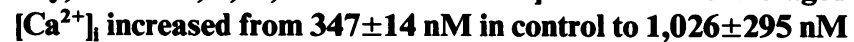
4 min after free radical generation (means \pm SEM, $n=7$ ), and remained elevated thereafter. We conclude that free radicals induce clear-cut, specific derangements of cellular metabolism in the form of glycolytic inhibition and calcium overload. The observed increase in $\left[\mathrm{Ca}^{2+}\right]_{1}$ suggests that the deleterious effects of free radicals are at least partially mediated by secondary changes in cellular calcium homeostasis. (J. Clin. Invest. 1991. 88:1014-1025.) Key words: calcium metabolism • contracture • glycolysis • hydroxyl radical • reperfusion injury
\end{abstract}

\section{Introduction}

Free radicals are attractive candidates in the continuing search for the mediators of reperfusion injury. Several lines of evidence support a dominant role for these highly reactive molecules. Radicals are generated upon restoration of flow to ischemic myocardium (1-4); scavengers and enzymes that destroy radicals have been found to improve functional and metabolic recovery (5-8); and, finally, exogenous radical generation mim-

Address reprint requests to Dr. Marban, Division of Cardiology, Department of Medicine, Hunterian 116, The Johns Hopkins University School of Medicine, 725 N. Wolfe Street, Baltimore, MD 21205.

Received for publication 6 September 1990 and in revised form 18 March 1991.

J. Clin. Invest.

(c) The American Society for Clinical Investigation, Inc.

$0021-9738 / 91 / 09 / 1014 / 12 \$ 2.00$

Volume 88, September 1991, 1014-1025 ics various features of reperfusion injury, notably contractile dysfunction and ATP depletion $(9,10)$. Despite important exceptions to many of these observations (11-13), interest in the effects of free radicals remains great. Nevertheless, relatively little is known about the precise mechanisms by which radicals damage cells. Such information is desirable for basic reasons and to help guide strategies for myocardial protection in ischemic syndromes.

The simplest notion might be to suppose that radicals kill cells by creating nonspecific holes in lipid membranes, particularly the sarcolemma, but this idea has been challenged by various experimental findings. Direct recordings of membrane potential $(14,15)$ and ionic currents $(9,16)$ during and after exposure to free radicals reveal surprisingly specific effects on ion transport pathways, with no evidence for the creation of nonspecific leaks. Goldhaber et al. (9) have found that radicals generated either by hydrogen peroxide or by xanthine + xanthine oxidase turn on ATP-sensitive potassium channels in the sarcolemma. Since these channels are thought to be preferentially regulated by ATP derived from glycolysis (rather than from oxidative phosphorylation), the observation that they are activated by exogenous free radicals is suggestive of glycolytic inhibition (17). Indeed, key enzymes in the glycolytic cascade are known to be susceptible to inactivation by free radicals (18, 19). Changes in $\mathrm{Na}^{+} / \mathrm{Ca}^{2+}$ and $\mathrm{Na}^{+} / \mathrm{H}^{+}$exchange activity (20, $21)$, as well as in $\mathrm{Na}^{+} / \mathrm{K}^{+} \mathrm{ATPase}(22,23)$ have also been found in sarcolemmal vesicle preparations. These pathways for transmembrane ion flux directly or indirectly regulate the intracellular free $\mathrm{Ca}^{2+}$ concentration $\left(\left[\mathrm{Ca}^{2+}\right]_{i}\right)$. Changes in $\left[\mathrm{Ca}^{2+}\right]_{\mathrm{i}}$ feature prominently in most diagrams that purport to explain the effects of radicals (24), although there is little direct evidence for radical-induced calcium overload. Disruption of calcium metabolism has been suspected for two reasons. First, $\left[\mathrm{Ca}^{2+}\right]_{\mathrm{i}}$ functions physiologically to activate contraction; disturbances in cellular $\mathrm{Ca}^{2+}$ cycling underlie many well-characterized forms of functional depression (25-27). Secondly, a sustained rise in $\left[\mathrm{Ca}^{2+}\right]_{i}$ can produce cellular injury by activating dormant proteases and by interacting with other enzymatic pathways (28). An effect of free radicals on $\left[\mathrm{Ca}^{2+}\right]_{i}$ would go a long way towards explaining the action of these compounds on the heart, particularly if the changes in $\left[\mathrm{Ca}^{2+}\right]_{\mathrm{i}}$ could be related to well-defined alterations in energy metabolism.

We sought evidence for radical-induced changes in calcium and energy metabolism using the most direct approach available in living tissue. Rabbit hearts were perfused in a nuclear magnetic resonance (NMR) ${ }^{1}$ magnet for measurements of

1. Abbreviations used in this paper: DMPO, 5,5'-dimethyl-1- $N$-pyroline-oxide; EPR, electron paramagnetic resonance; 5F-BAPTA, 5,5'difluoro derivative of 1,2-bis(o-aminophenoxy) ethane- $N, N, N^{\prime}, N^{\prime}$-tetraacetic acid; NMR, nuclear magnetic resonance; NTA, nitrilo-triacetic acid. 
$\left[\mathrm{Ca}^{2+}\right]_{\mathrm{i}}$ and high-energy phosphates. Radicals were generated by the superoxide-driven Fenton reaction, alternatively known as the iron-catalyzed Haber-Weiss reaction. Hydrogen peroxide is a potent oxidizing agent which generates superoxide anion $\left(\cdot \mathrm{O}_{2}^{-}\right)$and hydroxyl radical $(\cdot \mathrm{OH})$ in the presence of transition metal ions (e.g., $\mathrm{Fe}^{3+}, \mathrm{Cu}^{2+}$ ). The superoxide anion dismutates in aqueous solution to yield $\mathrm{H}_{2} \mathrm{O}_{2}$ and $\mathrm{O}_{2}$ via the reaction (29),

$2 \cdot \mathrm{O}_{2}^{-}+2 \mathrm{H}^{+} \rightarrow \mathrm{H}_{2} \mathrm{O}_{2}+\mathrm{O}_{2}$

In the presence of transition metals, $\mathrm{H}_{2} \mathrm{O}_{2}$ and $\cdot \mathrm{O}_{2}^{-}$react to generate more of the hydroxyl radical via the Fenton and Haber-Weiss reactions (29),

$\cdot \mathrm{O}_{2}^{-}+\mathrm{Fe}^{3+} \rightarrow \mathrm{O}_{2}+\mathrm{Fe}^{2+}$

$\mathrm{H}_{2} \mathrm{O}_{2}+\mathrm{Fe}^{2+} \rightarrow \cdot \mathrm{OH}+\mathrm{OH}^{-}+\mathrm{Fe}^{3+}$

to yield the following net reaction:

$\cdot \mathrm{O}_{2}^{-}+\mathrm{H}_{2} \mathrm{O}_{2} \rightarrow \cdot \mathrm{OH}+\mathrm{OH}^{-}+\mathrm{O}_{2}$

Our observations provide the first direct evidence for concomitant disruption of calcium and energy metabolism by free radicals.

\section{Methods}

Female New Zealand white rabbits $(1.5-2.0 \mathrm{~kg})$ were heparinized and anesthetized with pentobarbital (65 mg s.c.). The hearts were excised and the aortae cannulated for Langendorff perfusion at $30^{\circ} \mathrm{C}$. The perfusate was a modified Krebs solution containing (in millimolar): $117 \mathrm{NaCl}, 24.6 \mathrm{NaHCO}_{3}, 5.9 \mathrm{KCl}, 1.2 \mathrm{MgCl}_{2}, 0.5$ EDTA, 16 glucose, and $0.5 \mathrm{CaCl}_{2}$, bubbled with $95 \% \mathrm{O}_{2} / 5 \% \mathrm{CO}_{2}$ to $\mathrm{pH} 7.40$ at $30^{\circ} \mathrm{C}$. Coronary flow was adjusted to achieve an initial coronary perfusion pressure, measured at the aortic cannula, of $65-70 \mathrm{~mm} \mathrm{Hg}$, then kept constant throughout the experiment. A latex balloon was passed into the left ventricle across the mitral valve and inflated with an aqueous standard solution of $6 \mathrm{~F}$-tryptophan for ${ }^{19} \mathrm{~F}$-NMR experiments $(12 \mathrm{mM})$ or trimetaphosphate $(10 \mathrm{mM})$ for ${ }^{31} \mathrm{P}-\mathrm{NMR}$ experiments to an end-diastolic pressure of $10 \mathrm{~mm} \mathrm{Hg}$. Isovolumic left ventricular pressure was recorded via a Statham P23DB pressure transducer (Gould Inc., Indianapolis, IN). The atria were trimmed away, the atrioventricular (AV) node was crushed with a blunt hemostat clamp, and hearts were paced at $0.5 \mathrm{~Hz}$ with an agar- $\mathrm{KCl}$ wick placed into the right ventricle.

Experimental protocol. A total of 20 hearts (average heart weight $3.0 \mathrm{~g}$ ) were studied. 5-10 min after the hearts achieved a steady-state left ventricular pressure during perfusion with the Krebs solution, the following protocol was implemented. An aqueous solution of $\mathrm{Fe}^{3+}-\mathrm{ni}-$ trilo-triacetic acid (NTA) (1:2), prepared as reported previously (30), was infused via a side port connected to the main perfusate column to achieve a final concentration of $100 \mu \mathrm{M}$. After $1 \mathrm{~min}, 0.75 \mathrm{mM} \mathrm{H}_{2} \mathrm{O}_{2}$ was added to the main perfusate line. Perfusion with both $\mathrm{Fe}^{3+}$-NTA and $\mathrm{H}_{2} \mathrm{O}_{2}$ continued for $4 \mathrm{~min}$, followed by a resumption of perfusion with the usual Krebs solution.

A total of 11 hearts (seven at $30^{\circ} \mathrm{C}, 0.5 \mathrm{mM}[\mathrm{Ca}]_{0}$; three at $30^{\circ} \mathrm{C}, 1$ $\mathrm{mM}[\mathrm{Ca}]_{\circ}$; one at $37^{\circ} \mathrm{C}, 1 \mathrm{mM}[\mathrm{Ca}]_{\circ}$ ) were loaded with calcium indicator 5F-BAPTA (see below) and dedicated to the measurement of timeaveraged $\left[\mathrm{Ca}^{2+}\right]_{i}$ using ${ }^{19} \mathrm{~F}$-NMR spectroscopy. Measurements of phosphorus metabolites were also obtained using ${ }^{31} \mathrm{P}-\mathrm{NMR}$ at the beginning and end of the experimental protocol. Two hearts loaded with 5FBAPTA $\left(30^{\circ} \mathrm{C}, 0.5 \mathrm{mM}[\mathrm{Ca}]_{o}\right)$ were used to measure phosphorus metabolites throughout the course of the experiment. Another seven hearts were studied without 5F-BAPTA to collect ${ }^{31}$ P-NMR spectra every 4 min during the entire experimental protocol, using phosphorus NMR parameters described below. Three of these hearts were also used to measure lactate levels on venous effluents collected every 4 min by an enzymatic method (Sigma Diagnostics Kit 826-UV, Sigma Chemical Co., St. Louis), and finally subjected to cytoplasmic extraction for the identification of phosphomonoester compounds.

Fluorine NMR measurements of intracellular calcium concentration. The hearts were lowered into the bore of a superconducting magnet (8.5 Tesla) connected to an NMR spectrometer (AM-360, Bruker Instruments, Inc., Billerica, MA) operated in the pulsed Fourier transform mode. The calcium indicator 5F-BAPTA [the 5,5'-difluoro derivative of 1,2-bis( $O$-aminophenoxy)ethane- $N, N, N^{\prime}, N^{\prime}$-tetraacetic acid] was loaded by perfusion with its tetra-acetoxymethyl ester derivative $(5 \mathrm{~F}$ BAPTA-AM, $7.5 \mu \mathrm{M}$ for $20 \mathrm{~min}$ at $30^{\circ} \mathrm{C}$, lot no. 9B; Molecular Probes, Inc., Eugene, OR), after which the perfusate was changed back to the modified Krebs solution $\left(0.5 \mathrm{mM}[\mathrm{Ca}]_{\mathrm{o}}\right)$. Free induction decays were accumulated at a spectral width of $5 \mathrm{kHz}$ using $70^{\circ}$ pulses every $0.4 \mathrm{~s}$ and averaged over $240 \mathrm{~s}$. The chemical shifts were referenced with respect to the $6 \mathrm{~F}$-tryptophan signal, assigned to $0 \mathrm{ppm}$. $\left[\mathrm{Ca}^{2+}\right]_{\mathrm{i}}$ is calculated according to the equation: $\left[\mathrm{Ca}^{2+}\right]_{\mathrm{i}}=K_{\mathrm{d}} \times[B] /[F]$ as previously described $(31,32)$. The $K_{d}$ value of $285 \mathrm{nM}$ previously measured at $30^{\circ} \mathrm{C}$ in EGTA-buffered solutions $(32,33)$ was used to calibrate the signals.

To confirm that the $\mathrm{Ca}^{2+}$ affinity of 5F-BAPTA would not change even if some of the indicator were exposed to free radicals in the course of the experiment, we obtained ${ }^{19} \mathrm{~F}$-NMR spectra of an EGTA-buffered calibrating solution before and during free radical generation by xanthine $(0.12 \mathrm{mM})+$ xanthine oxidase $(1.2 \mathrm{U} / 50 \mathrm{ml})+\mathrm{H}_{2} \mathrm{O}_{2}(1 \mathrm{mM})$. This combination was designed to produce superoxide and hydroxyl radicals (34) without introducing any divalent cations that might themselves bind to 5F-BAPTA (31). No change in the ${ }^{19} \mathrm{~F}$-NMR spectra could be detected as a consequence of exposure to the free radical-generating system (data not shown), providing evidence that the $\mathrm{Ca}^{2+}$ indicator itself is not altered by free radicals.

Phosphorus NMR measurements of energy metabolites. Minimally saturated ${ }^{31} \mathrm{P}$-NMR spectra were obtained at a spectral width of $6 \mathrm{kHz}$ using $45^{\circ}$ pulses delivered at 2-s intervals. Spectra were processed as previously described (35). The amounts of inorganic phosphate $\left(\mathrm{P}_{\mathrm{i}}\right)$, phosphocreatine (PCr), and ATP in the myocardium were obtained by planimetry under individual peaks using a digitizer. The areas were normalized by that for the magnesium trimetaphosphate standard in the left ventricular balloon and expressed as micromole per gram wet weight. In those hearts not containing trimetaphosphate as a standard (i.e., those dedicated primarily to ${ }^{19} \mathrm{~F}$-NMR measurements), the tissue contents of $P_{i}, P C r$, and ATP were expressed as the percentage of the area under the ATP peak during the initial control period in each individual experiment (36). The chemical shifts are reported as ppm from the $\mathrm{PCr}$ peak. The $\mathrm{pH}_{\mathrm{i}}$ was determined from the shift between $\mathrm{P}_{\mathrm{i}}$ and $\mathrm{PCr}$ resonances.

Identification of phosphomonoester peaks. At the end of the experiment three hearts were immediately clamped frozen and immersed in liquid nitrogen. The hearts were individually weighed and extracted with $6 \%$ perchloric acid $(2 \mathrm{ml} / \mathrm{g}$ wet weight). The supernatant extract was neutralized with $5 \mathrm{M} \mathrm{KOH}$ to a $\mathrm{pH}$ of 7.0-7.5. After centrifugation, $0.1 \mathrm{~g} / \mathrm{ml}$ of a chelating resin (Sigma Chemical Co. C-7901) was added to the supernatant to remove metal ions. The decanted extract was lyophilized and reconstituted in $\mathrm{D}_{2} \mathrm{O}$ before NMR analysis.

Phosphorus NMR spectra were obtained from the extract using an NMR spectrometer (model MSL 500, Bruker Instruments, Inc.). The identification of the major phosphomonoester peak centered at $\sim 7$ ppm in whole perfused hearts was determined in the following manner: (a) the observed resonances were compared to a library of resonance peak positions according to existing published data $(37-39),(b)$ the $\mathrm{pH}$ dependences of the chemical shifts in the extract were determined for the various peaks of interest, and pK.'s derived from the HendersonHasselbach relationship, and $(c)$ suspected identity of the major peaks was confirmed by the addition of a known phosphate compound to the extract to determine if the resonance peak originating from the added substance enhanced the peak of interest at several different $\mathrm{pH}$ values (40). 
Electron paramagnetic resonance measurements of free radicals. EPR spectra were recorded at room temperature using a spectrometer (model ER300, IBM-Bruker) operating at X-band with a TM 110 cavity and TM flat cell (Bruker Instruments, Inc.). The spectrometer settings were: modulation frequency, $100 \mathrm{kHz}$; modulation amplitude, $0.5 \mathrm{G}$; scan time, $1.0 \mathrm{~min}$; microwave power, $20 \mathrm{~mW}$; microwave frequency, $9.772 \mathrm{GHz}$. The microwave frequency and magnetic field were precisely measured with a source-locking microwave counter (model 575, EIP Instruments, San Jose, CA) and an NMR gaussmeter (model ER 035M, Bruker Instruments, Inc.), respectively.

Repetitive 1-min acquisitions were performed and the digitized spectral data transferred to a personal computer for analysis. Spectral simulations were done on the personal computer and directly matched with the experimental data to extract the spectral parameters. Multipurpose computer software capable of simulating and handling as many as $\mathbf{2 4}$ simulated and/or experimental spectra at a time was used for analyzing and quantitating experimental spectra, as described previously $(30,41,42)$.

Statistics. All pooled data are presented as means \pm SEM. Statistical analysis was performed using paired $t$ test or analysis of variance as appropriate (43). Significance was determined at the $P<0.05$ level.

\section{Results}

Identity and quantitation of free radicals generated by $\mathrm{H}_{2} \mathrm{O}_{2}$ $+\mathrm{Fe}^{3+}$. Electron paramagnetic resonance measurements were performed in order to confirm that the radical generating system actually produced the reactive $\cdot \mathrm{OH}$ radical both in vitro and upon perfusion into isolated hearts. In the presence of iron chelates which facilitate the Fenton reaction, $\mathrm{H}_{2} \mathrm{O}_{2}$ is reduced to $\cdot \mathrm{OH}$ as shown in reaction 4 . The iron-mediated Fenton reaction of $\mathrm{H}_{2} \mathrm{O}_{2}$ to $\cdot \mathrm{OH}$ is believed to be an important source of the oxidative injury which occurs upon reperfusion of the ischemic heart $(1,6)$. Fig. $1 \mathrm{~A}$ shows the EPR spectra obtained when the ferric iron chelate $\mathrm{Fe}^{3+}-\mathrm{NTA}$ and $\mathrm{H}_{2} \mathrm{O}_{2}$ were mixed in the presence of the EPR spin trap 5,5'dimethyl-1- $N$-pyrolineoxide (DMPO). A prominent 1:2:2:1 quartet signal is evident, which is well-simulated by a spectrum with hyperfine coupling constants $a_{\mathrm{H}}=14.71$ and $a_{\mathrm{N}}=14.99 \mathrm{G}$ (Fig. $1 \mathrm{~B}$ ) characteristic of DMPO-OH (44). With either $\mathrm{H}_{2} \mathrm{O}_{2}$ or $\mathrm{Fe}^{3+}$-NTA alone in the presence of DMPO, no significant radical signal was seen. These experiments suggest that $\cdot \mathrm{OH}$ is generated on mixing $\mathrm{Fe}^{3+}$-NTA and $\mathrm{H}_{2} \mathrm{O}_{2}$ and reacts with DMPO to form DMPO$\mathrm{OH}$. In addition, it appears that $\mathrm{H}_{2} \mathrm{O}_{2}$ alone or the iron chelate alone give rise to little if any radical generation.

In order to confirm further that $\cdot \mathrm{OH}$ is generated, additional experiments were performed in the presence of ethanol. The hydroxyl radical will extract a hydrogen from ethanol to form an ethyl radical which gives rise to a DMPO-ethyl adduct signal. Fig. $1 C$ shows that, in the presence of $5 \%$ ethanol, a prominent 1:1:1:1:1:1 six peak spectrum, with $a_{\mathrm{H}}=23.29$ and $a_{\mathrm{N}}=15.90$ (Fig. $1 \mathrm{D}$ ), was observed; this signal is indicative of the DMPO ethyl adduct with a decrease in the magnitude of the DMPO-OH spectrum. These spectra demonstrate that an ethyl radical was generated and thus confirm that $\cdot \mathrm{OH}$ had been formed.

Additional experiments were performed perfusing $\mathrm{H}_{2} \mathrm{O}_{2}$ and $\mathrm{Fe}^{3+}$-NTA into isolated rabbit hearts along with $40 \mathrm{mM}$ DMPO, and free radical generation was measured in the coronary effluent. The free radical signals (Fig. $2 \mathrm{~A}$ ) were similar to those observed in the in vitro studies, consisting of a prominent DMPO-OH signal and a DMPO-R signal, as exemplified by Fig. $2 B$. Comparison with $A$ shows that these signals are quite

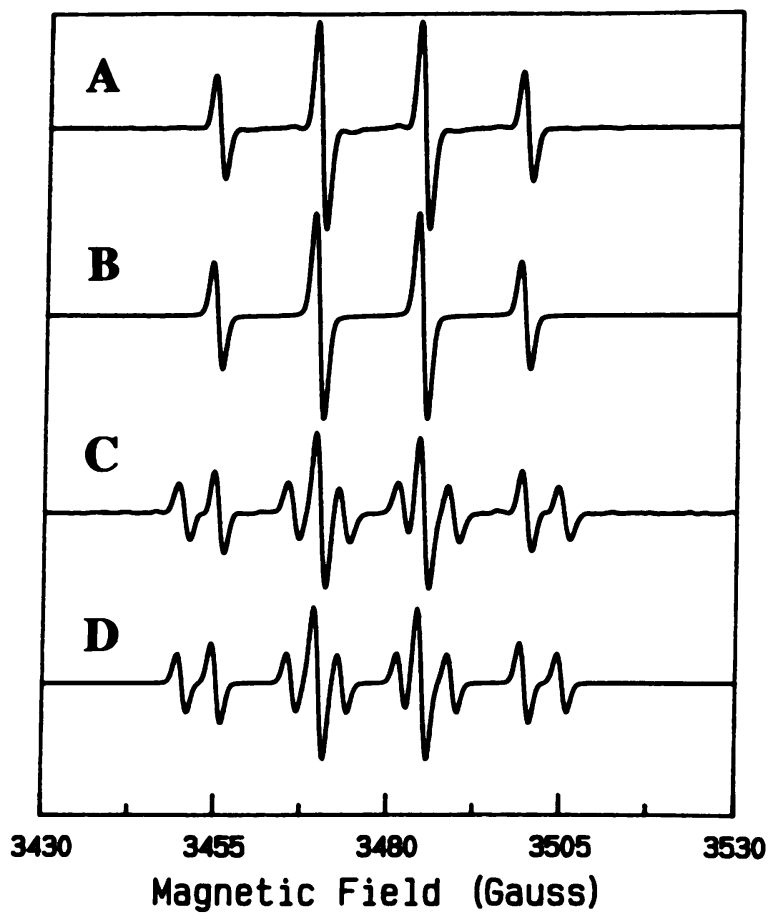

Figure 1. Identity of the radical species produced by $\mathrm{H}_{2} \mathrm{O}_{2}+\mathrm{Fe}^{3+}$ NTA. $(A)$ EPR spectrum of $\mathrm{H}_{2} \mathrm{O}_{2}+\mathrm{Fe}^{3+}-\mathrm{NTA}, \cdot \mathrm{OH}$ generating system in the presence of $50 \mathrm{mM}$ DMPO. (B) A simulation of spectrum in $A$ with $a_{\mathrm{H}}=14.99 \mathrm{G}, a_{\mathrm{N}}=14.71 \mathrm{G}, 15.0 \mathrm{G}$ and linewidth $=1.45$ G. (C) Identical to $A$ except for the addition of $5 \%$ ethanol. (D) Simulation of spectrum in $C$ consisting of a linear combination of DMPO-OH, $a_{\mathrm{H}}=14.99 \mathrm{G}, a_{\mathrm{N}}=14.71 \mathrm{G}$, linewidth $=1.45 \mathrm{G}$ with a weight of 0.58 , and DMPO-ethyl $a_{\mathrm{H}}=23.29, a_{\mathrm{N}}=15.9 \mathrm{G}$, linewidth $=1.45 \mathrm{G}$ with a weight of 0.42 .

similar to those observed on postischemic reperfusion $(1,42)$. With $\left[\mathrm{H}_{2} \mathrm{O}_{2}\right]$ in the range of $0.5-0.75 \mathrm{mM}$, the intensity of the observed radical signals corresponded to a total radical concentration of $\sim 1.0 \mu \mathrm{M}$, which matched the peak concentration observed in rabbit hearts reperfused after $30 \mathrm{~min}$ ischemia (note that the two spectra in Fig. 2 have been scaled equally).

Effects of free radicals on contractile pressure. After having confirmed that our free radical generating system produces . $\mathrm{OH}$ in concentrations comparable to those observed in postischemic reperfusion, we proceeded to characterize the functional consequences of the free radicals. Fig. $3 \mathrm{~A}$ shows a typical pressure recording obtained from a heart that had not been loaded with 5F-BAPTA. Function was stable before free radical generation. The systolic pressure of $60 \mathrm{~mm} \mathrm{Hg}$ reflects the extracellular calcium concentration, which was only $0.5 \mathrm{mM}$; a low concentration was chosen to prevent any possible bias in our experimental conditions in favor of calcium overload. $\mathrm{Fe}^{3+}$-NTA was infused alone before the addition of $\mathrm{H}_{2} \mathrm{O}_{2}$ at the time indicated above the pressure record. The $\mathrm{Fe}^{3+}-\mathrm{NTA}$ alone produced a small increase in contractile pressure in this heart, an effect which was not observed consistently. After 1 min the infusion of $\mathrm{H}_{2} \mathrm{O}_{2}$ was started and continued concomitantly with $\mathrm{Fe}^{3+}$-NTA. Early during the 4-min exposure to $\mathrm{H}_{2} \mathrm{O}_{2}$ and $\mathrm{Fe}^{3+}$-NTA together, systolic pressure dropped slightly, and diastolic pressure showed little change. Towards the end of the infusion, however, systolic pressure fell dramatically and diastolic pressure began to rise. The rise in diastolic pressure con- 


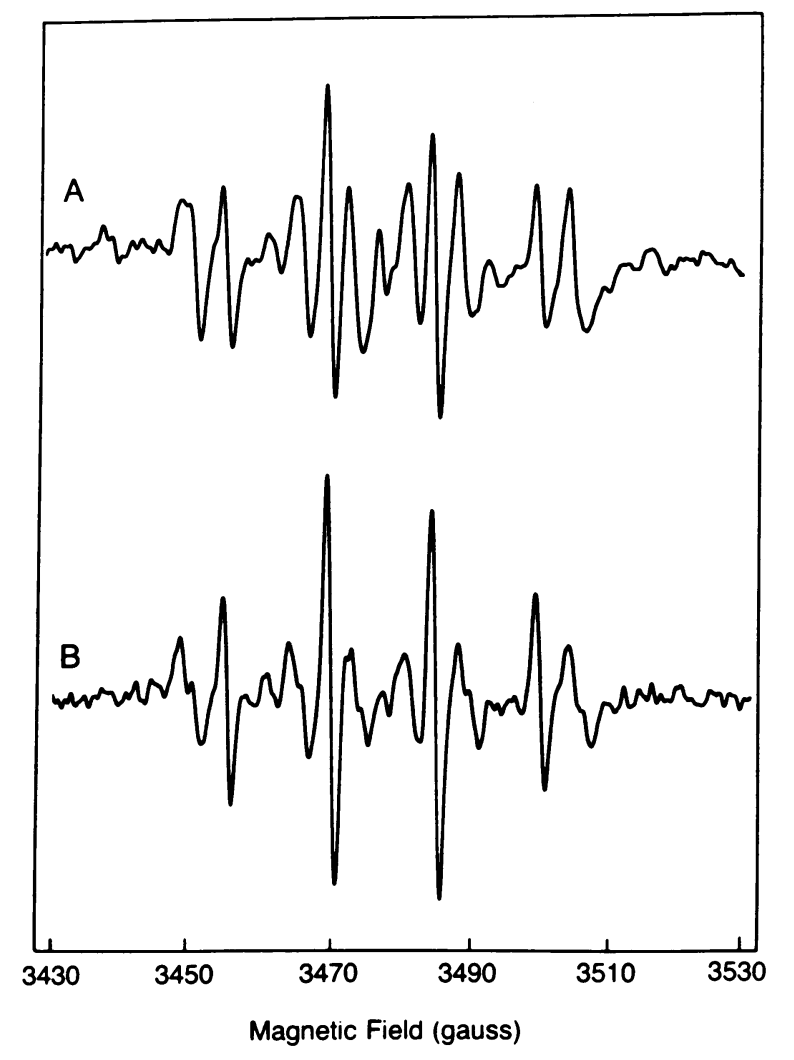

Figure 2. EPR spin trapping experiments of two separate rabbit hearts perfused with $40 \mathrm{mM}$ DMPO. (A) EPR spectrum of coronary effluent collected 10-20 s after reperfusion after $30 \mathrm{~min}$ of global ischemia. $(B)$ An identically recorded and scaled spectrum from a heart perfused with the $\cdot \mathrm{OH}$ radical generating system consisting of $100 \mu \mathrm{M} \mathrm{Fe}^{3+}$. NTA and $0.75 \mathrm{mM} \mathrm{H}_{2} \mathrm{O}_{2}$.

tinued progressively throughout the period of observation, even after the $\mathrm{H}_{2} \mathrm{O}_{2}$ infusion was terminated. The net result was a marked decrease in developed pressure (defined as peak-systolic minus end-diastolic pressure) which continued to evolve even after return to control perfusate.

The lower panel (Fig. 3 B) demonstrates pooled data from 4 such hearts illustrating the average time course of the changes in systolic and diastolic pressure. Developed pressure (plotted in Fig. 8) revealed a statistically significant depression from control starting at $4 \mathrm{~min}$ after $\mathrm{H}_{2} \mathrm{O}_{2} .10 \mathrm{~min}$ after the end of $\mathrm{H}_{2} \mathrm{O}_{2}$ exposure, absolute diastolic pressure was also significantly different from control. Thus, contractile depression began during the infusion of free radicals. Afterwards, full-blown contracture developed despite termination of the radical-generating infusion. The contractile failure evident in Fig. 3, which is reminiscent of ischemic $(24,45)$ or postischemic contracture (46), results from mechanisms yet to be defined. The two most obvious possibilities are (a) depletion of intracellular [ATP] to a level sufficiently low to lock the crossbridges in the noncycling rigor state (45), and $(b)$ elevation of $\left[\mathrm{Ca}^{2+}\right]_{i}$ with force generation by the physiological mechanism of $\mathrm{Ca}^{2+}$-activated cross-bridge cycling (24). ATP depletion has been reported as a consequence of exposure to exogenous free radicals $(9,19)$, but the reported depletion in bulk ATP to $\sim 50 \%$ of control levels would not in itself suffice to produce contracture (45). On the other hand, several reports point to calcium overload as an
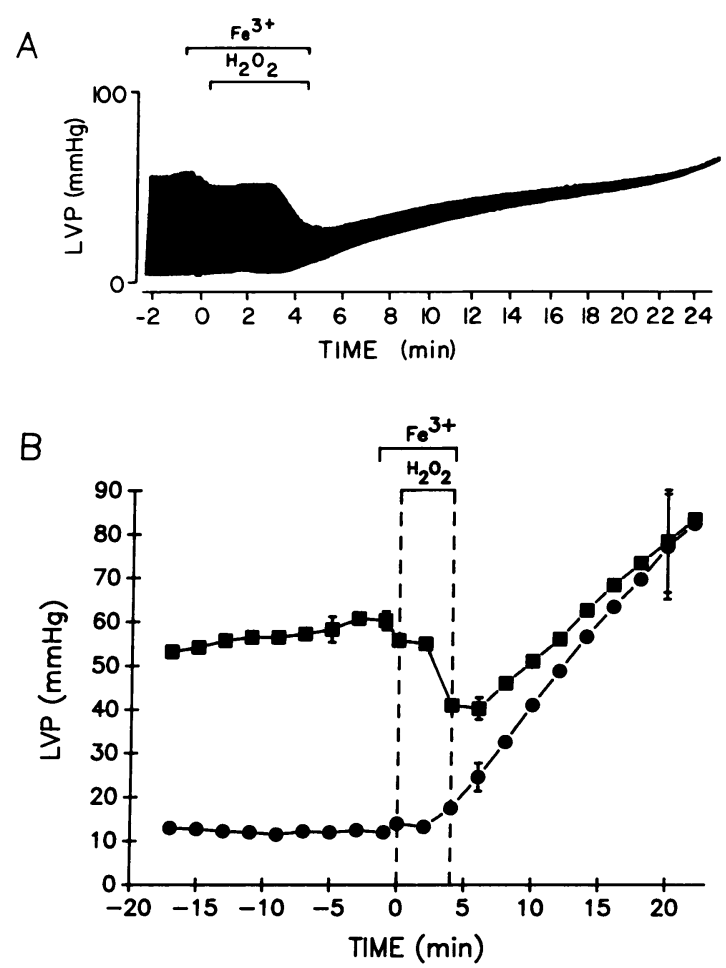

Figure 3. Effects of free radicals on contractile force generation. $(A)$ Record of isovolumic left ventricular pressure from a Langendorffperfused rabbit heart exposed to $\mathrm{H}_{2} \mathrm{O}_{2}(0.75 \mathrm{mM}) / \mathrm{Fe}^{3+}$-NTA $(100$ $\mu \mathrm{M})$, and not loaded with 5F-BAPTA. (B) Pooled data from four hearts not loaded with 5F-BAPTA illustrating the changes in peak systolic ( $\bullet$ and end-diastolic $(\bullet)$ pressure over the time course of the experimental protocol. Mean values are shown for each interval; only a few representative error bars (SEM) are shown for clarity. LVP, left ventricular pressure.

important consequence of free radical exposure $(16,47,48)$. Various lines of evidence additionally suggest that glycolytic ATP production plays a crucial role in maintaining ion homeostasis across the sarcolemma $(17,24,49)$. Thus, we sought to observe the interrelationship of energy metabolites, $\left[\mathrm{Ca}^{2+}\right]_{i}$ and function during and after the generation of free radicals. We measured phosphorus-containing metabolites both in the absence and presence of 5F-BAPTA to control for possible effects of cytoplasmic calcium buffering, which is known to be substantial with this indicator (33).

Metabolism: effect of free radicals on high energy phosphates. Fig. 4 demonstrates typical phosphorus NMR spectra from one heart $(A)$ during control perfusion, $(B) 4$ min after infusion of $\mathrm{H}_{2} \mathrm{O}_{2}+\mathrm{Fe}^{3+}$, and $(C)$ after 20 min of washout. The effects of free radicals are dramatic. As early as $4 \mathrm{~min}(B)$, a decrease in $\mathrm{PCr}$ is evident, with a concomitant rise in $\mathrm{P}_{\mathrm{i}}$. ATP has decreased noticeably by $20 \mathrm{~min}$ after free radical infusion. Of particular interest is the marked increase in the chemical resonance peak at $\sim 7 \mathrm{ppm}$, known as the phosphomonoester resonance, evident in both $B$ and $C$, suggesting an increase in sugar phosphates from glycolytic inhibition: Blockage of early steps in glycolysis leads to accumulation of phosphorylated sugars via direct inhibition of glyceraldehyde-3-phosphate dehydrogenase, and through reduction of the intracellular concentration and redox potential of its nicotinamide cofactors $(18,19)$. 
A

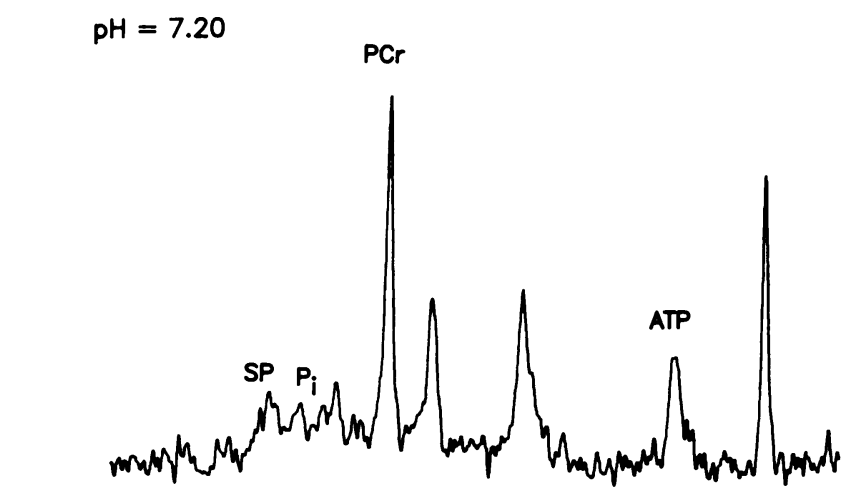

B

$\mathrm{PH}=7.14$

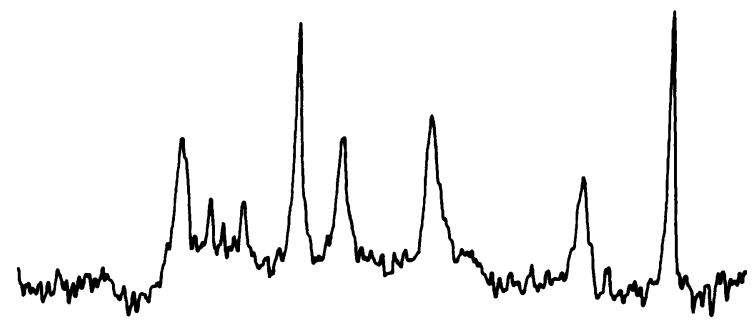

C

$\mathrm{pH}=7.01$

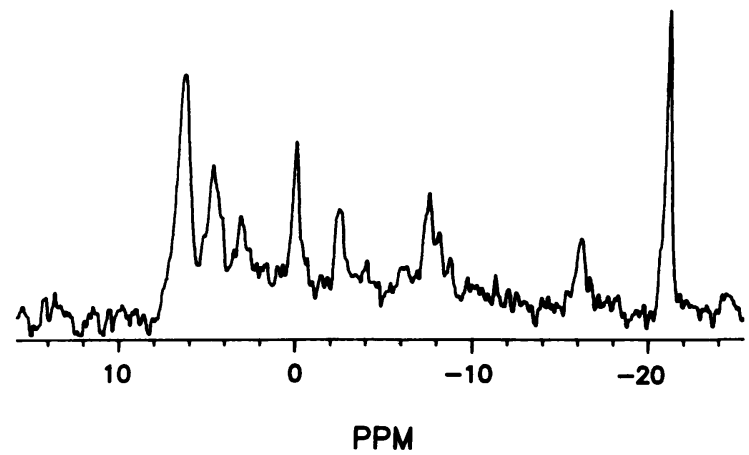

Figure 4. Representative phosphorus NMR spectra (4-min acquisition) from a heart during control perfusion $(A ;[\mathrm{PCr}]=5.89 \mu \mathrm{mol} / \mathrm{g}$ wet wt, $\left.[\mathrm{ATP}]=3.10,[\mathrm{SP}]=0.83,\left[\mathrm{P}_{\mathrm{i}}\right]=0.64\right), 4 \mathrm{~min}$ after infusion of $\mathrm{H}_{2} \mathrm{O}_{2}+\mathrm{Fe}^{3+}\left(B ;[\mathrm{PCr}]=3.74,[\mathrm{ATP}]=2.27,[\mathrm{SP}]=2.39,\left[\mathrm{P}_{\mathrm{i}}\right]\right.$ $=0.64$ ) and after 20 min of washout with $\mathrm{H}_{2} \mathrm{O}_{2}$-free and $\mathrm{Fe}^{3+}$-free perfusate $\left(C ;[\mathrm{PCr}]=2.18,[\mathrm{ATP}]=1.44,[\mathrm{SP}]=4.45,\left[\mathrm{P}_{\mathrm{i}}\right]=2.58\right)$. Peaks represent sugar phosphate (SP), inorganic phosphate $\left(\mathbf{P}_{\mathrm{i}}\right)$, phosphocreatine (PCr), ATP, and the standard trimetaphosphate (from left to right).

The phosphomonoesters encompass a variety of biological phosphates that overlap in their respective chemical shifts. Substantial evidence from biochemical assays and extracts document the elaboration of sugar phosphates, namely fructose 1,6-diphosphate, glyceraldehyde 3-phosphate, and dihydroxyacetone phosphate resulting from the build-up of glycolytic intermediates proximal to a block in the glycolytic pathway (18, $19,50,51)$. Other investigators have also identified the com- pounds phosphorylcholine and phosphorylethanolamine as prominent components in neonatal brain tissue and various tumors $(38,40,52,53)$, although not in striated muscle. Nevertheless, we sought to identify the compounds in our $\sim 7 \mathrm{ppm}$ peak explicitly as sugar phosphates to eliminate any ambiguity regarding the inhibition of glycolysis by free radicals.

Fig. 5 summarizes the steps leading to the identification of various compounds with overlapping chemical shifts at $\sim 7$
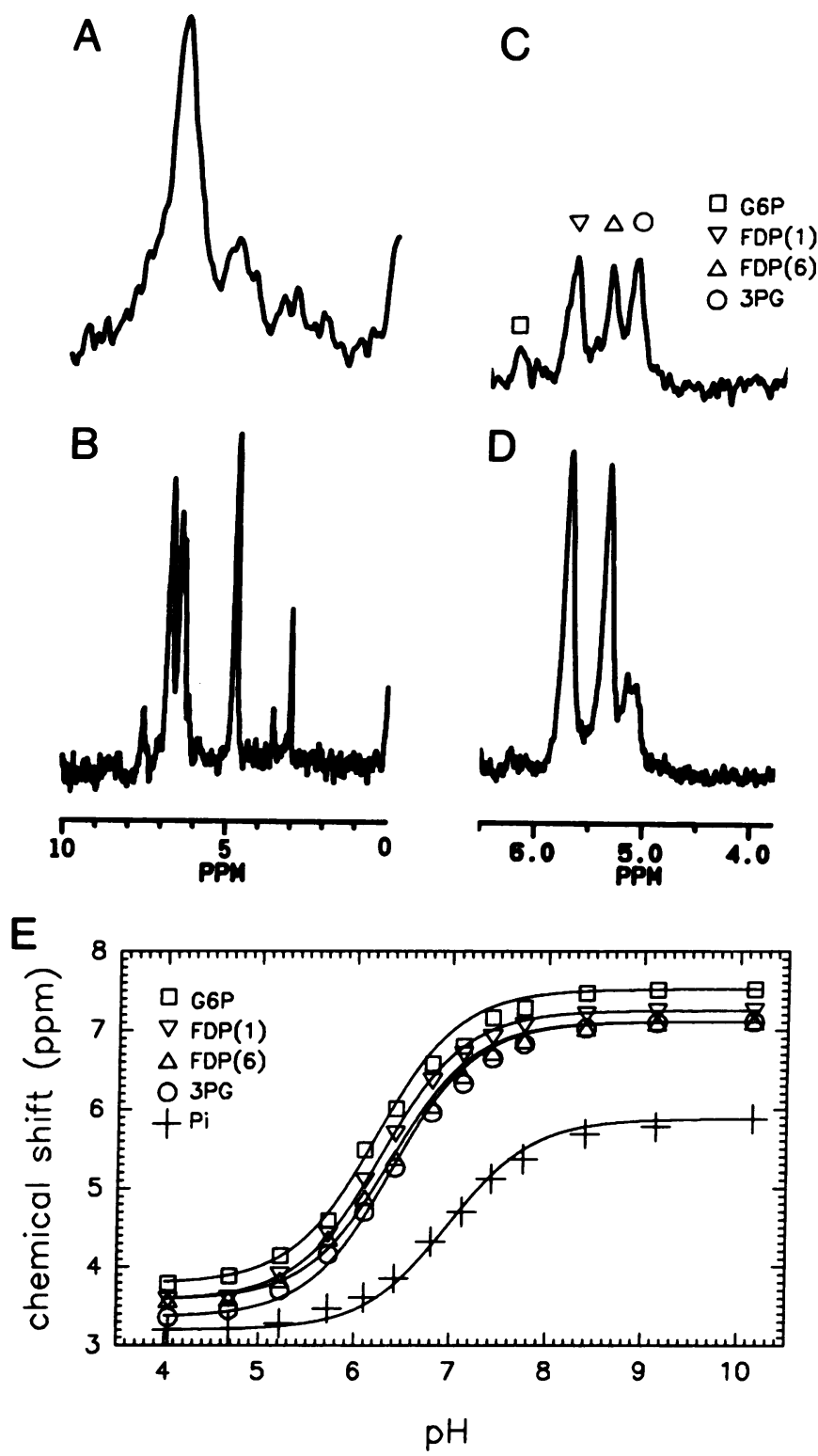

Figure 5. Identification of compounds in the phosphomonoester peak. $(A){ }^{31} \mathrm{P}$ spectrum from a whole heart, $\mathrm{pH}_{\mathrm{i}}=7.12$. (B) ${ }^{31} \mathrm{P}$ spectrum from the cytoplasmic extract of the same heart as in $A$ at pH $=7.12$. $(C)$ Separation of the extract resonances into distinct peaks at $\mathrm{pH}=6.08,(D)$ enhancement of peaks after addition of fructose 1,6-diphosphate $(\sim 4 \mathrm{mM}),(E) \mathrm{pH}$ dependence of chemical shifts. Solid curves were plotted after Henderson-Hasselbach equation with the following $\mathrm{pK}_{\mathrm{a}}$ : glucose 6-phosphate (G6P; $\left.\mathrm{pK}_{\mathrm{a}} 6.21\right)$, P-6 of fructose 1,6-diphosphate [FDP(6); pK, 6.27], P-1 of fructose 1,6-diphosphate [FDP(1); pK a 6.37], 3-phosphoglycerate (3PG; pK a 6.38). Line broadening factors are as follows: $(A) 25 \mathrm{~Hz},(B$ and $C) 3 \mathrm{~Hz},(D) 1$ $\mathrm{Hz}$. 
ppm. Panel $A$ is a ${ }^{31} \mathrm{P}-\mathrm{NMR}$ spectrum obtained from a representative heart that had been subjected to the free radical generating system, exhibiting a prominent phosphomonoester peak $\left(\mathrm{pH}_{\mathrm{i}} 7.12\right)$. Panel $B$ shows the ${ }^{31} \mathrm{P}-\mathrm{NMR}$ spectrum obtained from the extract of the same heart at $\mathrm{pH}$ 7.12. Because of the higher field strength and improved field homogeneity in the extract as opposed to the whole heart, the resonances are narrow and much better resolved. Panel $C$ shows a spectrum obtained from the extract at $\mathrm{pH} 6.08$, where the chemical shifts are even more distinct. Further identification was pursued by observing the $\mathrm{pH}$ dependence for the peaks of interest. Spectra were obtained over a pH range of 10.04-4.05, with alteration of the $\mathrm{pH}$ by $0.5-1.0 \mathrm{pH}$ units between successive spectra. Panel $E$ depicts the $\mathrm{pH}$ titration for the most prominent peaks. The $\mathrm{pK}_{\mathrm{a}}$ is the midpoint of each curve for each compound: glucose 6phosphate, $\mathrm{pK}_{\mathrm{a}}$ 6.21; fructose 1,6-diphosphate, $\mathrm{P}-6, \mathrm{pK}_{\mathrm{a}} 6.27$ and $\mathrm{P}-1, \mathrm{pK}_{\mathrm{a}}$ 6.37; 3-phosphoglycerate, $\mathrm{pK}_{\mathrm{a}} 6.38$, with the identities based on the literature (37). The identity of fructose 1,6-diphosphate was further confirmed by adding $4 \mathrm{mM}$ of this compound to the extract before obtaining another spectrum at pH 6.08. Panel $D$ illustrates the selective enhancement of the peaks which correspond to the phosphates at positions 1 and 6 of fructose 1,6-diphosphate [FDP(1) and FDP(6)]. Thus, these findings indicate that glycolytic intermediates represent the dominant components of the phosphomonoester peak that is observed in the radical-exposed hearts.

Fig. 6 summarizes the effects of free radicals on energy metabolites in the absence of 5F-BAPTA. Pooled data from four hearts demonstrate the changes in high-energy phosphates and $\mathrm{pH}_{\mathrm{i}}$ before, during and after infusion of $\mathrm{H}_{2} \mathrm{O}_{2}-\mathrm{Fe}^{3+}$. [ATP] decreases by $50 \%$ within $12-16 \mathrm{~min}$ after free radical infusion. The concentrations of $\mathrm{PCr}$ and $\mathrm{P}_{\mathrm{i}}$ exhibit reciprocal changes, concurrent with the drop in [ATP]. Sugar phosphate concentration begins to rise immediately after the infusion of peroxide and iron is terminated, and continues to increase thereafter. Intracellular $\mathrm{pH}$ does not change significantly throughout the time course of the experiment.

Comparison of Figs. 3 and 6 reveals that the contractile changes generally precede the marked changes in $P_{i}$, a metabolite which is known to depress myocardial force (35). Although ATP begins to decrease slightly during the $\mathrm{H}_{2} \mathrm{O}_{2}-\mathrm{Fe}^{3+}$ infusion, the contractile changes once again precede the decrease in [ATP]. Interestingly, the time course of accumulation of sugar phosphates (Fig. $6 C$ ) is most comparable to that of the contracture (cf. Fig. 3 B). Among the phosphorus metabolites measured in all hearts studied with and without 5F-BAPTA, the myocardial content of sugar phosphate showed the best correlation with end-diastolic pressure $(r=0.815, P<0.01)$.

Inhibition of glycolysis would decrease the production of lactate, although net lactate efflux might be enhanced if oxidative phosphorylation were also inhibited (9). To distinguish between these possibilities, we measured lactate levels in venous effluent samples obtained throughout the experimental protocol in three separate hearts. In all cases, venous lactate concentration remained below the limit of detection for the assay $(1.2 \mathrm{mg} / \mathrm{dl})$ throughout the time course of the experiment. Thus, our data provide no support for a disruption of oxidative phosphorylation superimposed upon the inhibition of glycolysis.

Effects of free radicals on hearts loaded with $5 F-B A P T A$. Considering the discrepancy between the time courses of ATP depletion and contracture, bulk ATP concentration appears

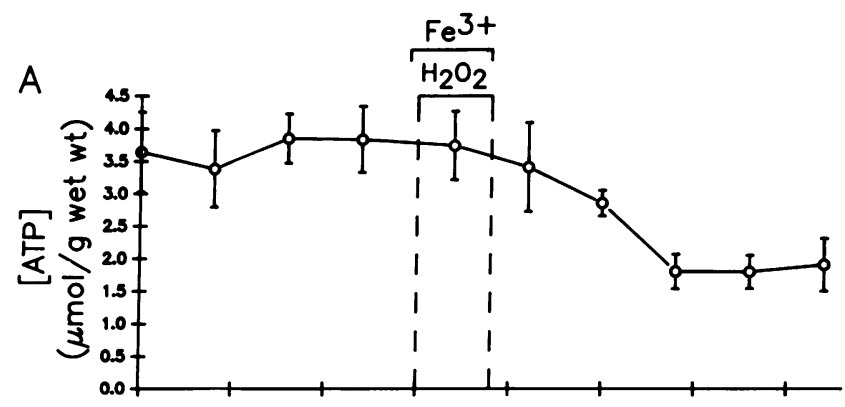

B
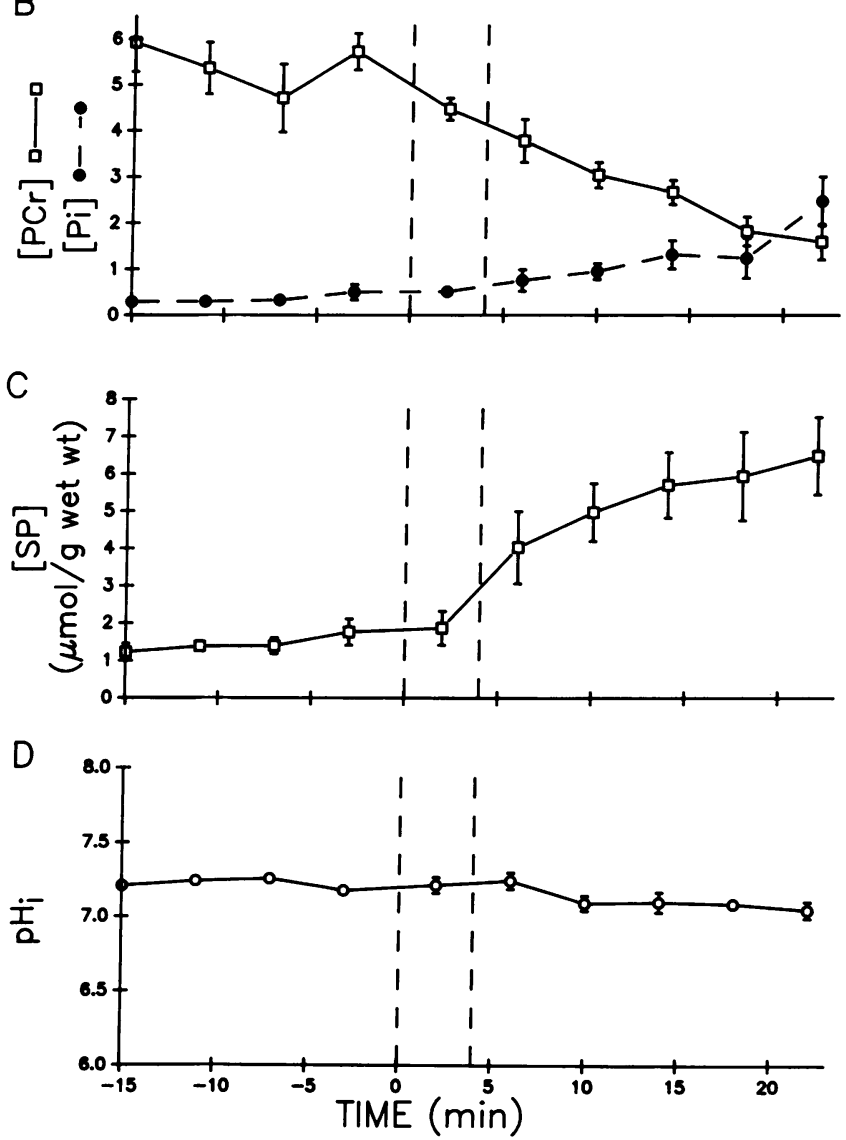

Figure 6. Pooled data for changes in high-energy phosphates and $\mathrm{pH}_{\mathrm{i}}$ $(A)$ [ATP], $(B)$ [PCr] (ם), [Pi] (๑). (C) [sugar phosphate]. (D) intracellular $\mathrm{pH}$. Means \pm SEM from four hearts not loaded with 5 F-BAPTA which contained a trimetaphosphate standard in the balloon.

incapable of explaining the mechanical changes. Since glycolysis is thought to regulate sarcolemmal ion transport, the evidence pointing to glycolytic inhibition in this study naturally gives reason to wonder whether $\left[\mathrm{Ca}^{2+}\right]_{\mathrm{i}}$ might be increased by free radicals. To test this idea, we loaded hearts with 5FBAPTA and measured the effects of free radicals on $\left[\mathrm{Ca}^{2+}\right]_{i}$.

The calcium-buffering capacity of 5F-BAPTA exerts a negative inotropic effect at the cytoplasmic concentrations required to achieve an acceptable signal-to-noise ratio (33). Nevertheless, we maintained a relatively low concentration of calcium $(0.5 \mathrm{mM})$ in the perfusate to prevent any potential bias in favor of calcium overload. Specifically, we elected not to compensate for the calcium buffering effect of 5F-BAPTA by increasing 
Table I. Mechanical Function and $\left[\mathrm{Ca}^{2+}\right]_{i}$ in Hearts Perfused with Different $[\mathrm{Ca}]_{o}$

\begin{tabular}{|c|c|c|}
\hline & {$[\mathrm{Ca}]_{0}, m M$} & 1.0 \\
\hline & \multicolumn{2}{|c|}{$m m \mathrm{Hg}$} \\
\hline \multicolumn{3}{|l|}{ Before 5F-BAPTA } \\
\hline Peak left ventricular pressure & $48.7 \pm 6.5$ & $67.3 \pm 10.1$ \\
\hline End-diastolic pressure & $9.0 \pm 1.1$ & $11.3 \pm 1.4$ \\
\hline \multirow{2}{*}{ Developed pressure } & $39.7 \pm 6.3$ & $56.0 \pm 10.0$ \\
\hline & \multicolumn{2}{|c|}{$m m \mathrm{Hg}$} \\
\hline \multicolumn{3}{|l|}{ After 5F-BAPTA } \\
\hline Peak left ventricular pressure & $31.0 \pm 4.4$ & $44.3 \pm 3.8$ \\
\hline End-diastolic pressure & $13.4 \pm 2.0$ & $15.7 \pm 4.0$ \\
\hline \multirow[t]{2}{*}{ Developed pressure } & $17.6 \pm 3.6$ & $28.6 \pm 7.3$ \\
\hline & \multicolumn{2}{|c|}{$n M$} \\
\hline$\left[\mathrm{Ca}^{2+}\right]_{\mathrm{i}}$ & $347 \pm 15$ & $397 \pm 51$ \\
\hline
\end{tabular}

Isovolumic left ventricular pressure before and after loading with $5 \mathrm{~F}$ BAPTA in hearts exposed to either $0.5 \mathrm{mM}[\mathrm{Ca}]_{\mathrm{o}}(n=7)$ or $1.0 \mathrm{mM}$ $[\mathrm{Ca}]_{0}(n=3)$ is summarized. Data are expressed as mean \pm SEM.

$[\mathrm{Ca}]_{0}$. Table I summarizes the functional data obtained in hearts studied in the absence and presence of 5F-BAPTA with either $0.5 \mathrm{mM}[\mathrm{Ca}]_{\circ}$ or $1.0 \mathrm{mM}[\mathrm{Ca}]_{0}$. Although $0.5 \mathrm{mM}[\mathrm{Ca}]_{\circ}$ is not physiological, the developed pressure is relatively well preserved at a level $>50 \%$ of that with $1.0 \mathrm{mM}[\mathrm{Ca}]_{o}$ in the absence of 5F-BAPTA. Also, the mean cytosolic $\left[\mathrm{Ca}^{2+}\right]_{\mathrm{i}}$ measured during control with $0.5 \mathrm{mM}[\mathrm{Ca}]_{o}$ in the buffer is not very different from that in $1.0 \mathrm{mM}[\mathrm{Ca}]_{\mathrm{o}}$, and is entirely consistent with previously reported time-averaged $\left[\mathrm{Ca}^{2+}\right]_{i}$ values in other species $(32,54)$.

Calcium buffering, when not offset by elevating $[\mathrm{Ca}]_{o}$, is known to be protective against $\mathrm{Ca}^{2+}$-mediated cellular injury such as that produced by frequent stimulation in neurons (55). We thus ascertained whether the changes in developed pressure and phosphorus metabolites remain at least qualitatively similar in hearts loaded with 5F-BAPTA as compared to hearts not containing the indicator. Fig. 7 demonstrates the pressure recording and representative ${ }^{31} \mathrm{P}-\mathrm{NMR}$ spectra from one heart loaded with 5F-BAPTA. The low systolic pressure reflects both the low free calcium in the perfusate, and the negative inotropic effect of 5F-BAPTA. Nevertheless, the contracture formation is quite comparable to that observed in hearts lacking $5 \mathrm{~F}$ BAPTA. The spectra in the lower panel were obtained from the same heart during control perfusion $(a)$, and 4-8 minutes $(b)$ or 12-16 min (c) after exposure to $\mathrm{H}_{2} \mathrm{O}_{2}$. A rise in the sugar phosphate peak $(\sim 7 \mathrm{ppm})$ can be noted as early as panel $b$, and the increase is even greater by the late phase of the experimental protocol (panel $c$ ). The decreases in $\mathrm{PCr}$ and ATP, with a concomitant rise in $P_{i}$, also contribute to a pattern that closely resembles that noted in hearts not loaded with 5F-BAPTA (cf. Fig. 4). Fig. 8 illustrates the average fractional changes in developed pressure during the experimental protocol in hearts loaded with 5F-BAPTA $(\Delta)$ and those not containing the indicator $(\square)$. In both sets of pooled data, developed pressure decreases during infusion of the free radical generating system

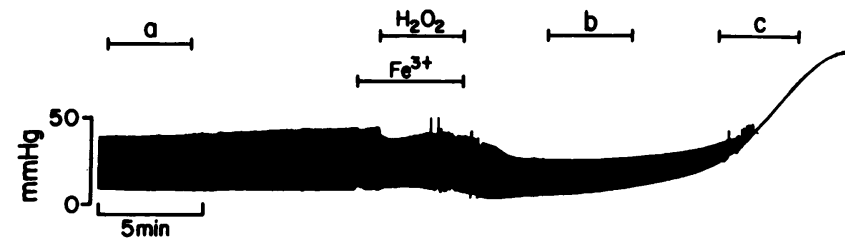

a.

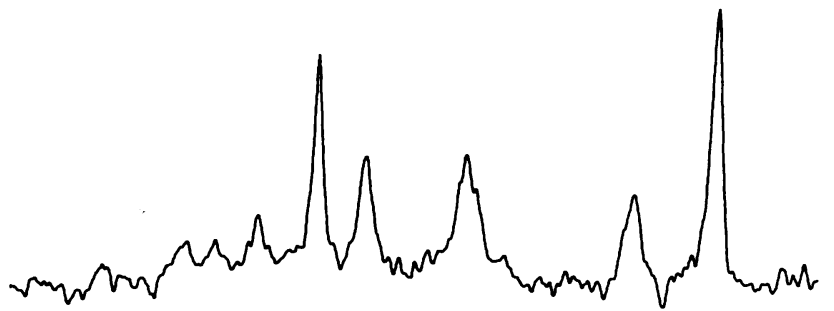

b.

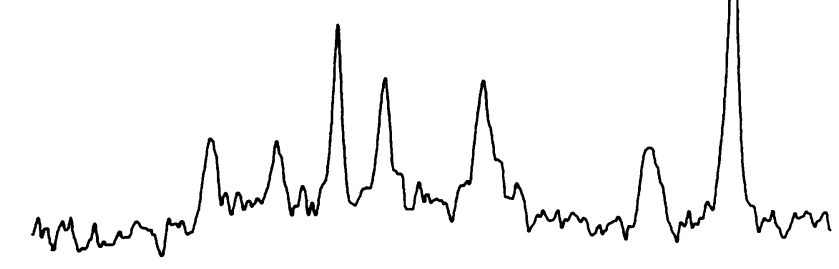

c.

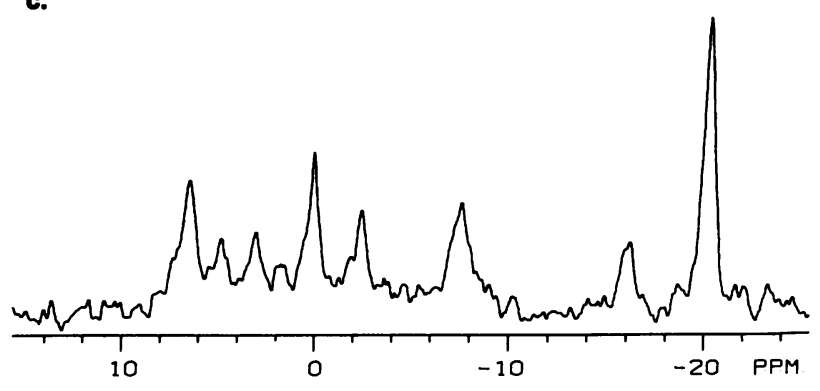

Figure 7. Effects of free radicals on contractile function and energy metabolism in a heart loaded with 5F-BAPTA. $(A)$ Record of isovolumic left ventricular pressure from a perfused rabbit heart loaded with 5F-BAPTA. $(B)$ Representative ${ }^{31} \mathrm{P}$ spectra obtained from the same heart during control perfusion $(a:[\mathrm{PCr}]=5.40 \mu \mathrm{mol} / \mathrm{g}$ wet weight, $\left.[\mathrm{ATP}]=3.48,[\mathrm{SP}]=1.36,\left[\mathrm{P}_{\mathrm{i}}\right]=1.07, \mathrm{pH}_{\mathrm{i}}=7.35\right), 4-8 \mathrm{~min}$ $\left(b:[\mathrm{PCr}]=4.48,[\mathrm{ATP}]=3.03,[\mathrm{SP}]=2.33,\left[\mathrm{P}_{\mathrm{i}}\right]=0.34, \mathrm{pH}_{\mathrm{i}}=7.23\right)$ and $12-16 \min \left(c:[\mathrm{PCr}]=3.32,[\mathrm{ATP}]=1.81,[\mathrm{SP}]=2.68,\left[\mathrm{P}_{\mathrm{i}}\right]\right.$ $\left.=1.19, \mathrm{pH}_{\mathrm{i}}=7.08\right)$ after peroxide exposure.

and continues to decline markedly thereafter. The relative decline is less pronounced $20 \mathrm{~min}$ after free radical infusion in 5F-BAPTA-loaded hearts, but the characteristic trend is quite similar. Thus, although we cannot exclude a protective effect from cytoplasmic 5F-BAPTA, such an effect is probably modest given that the overall patterns of the contractile and metabolic responses to free radicals are preserved.

To ascertain the interrelationship among metabolites, contractile function and calcium, we measured high-energy phosphates and $\mathrm{pH}_{\mathrm{i}}$ in the same hearts in which $\left[\mathrm{Ca}^{2+}\right]_{\mathrm{i}}$ was measured by 5F-BAPTA. Fig. 9 summarizes the changes in $\mathrm{pH}_{\mathrm{i}}$ and high-energy phosphates expressed as the percentage of the area under the control ATP peak in the absence or presence of cyto- 


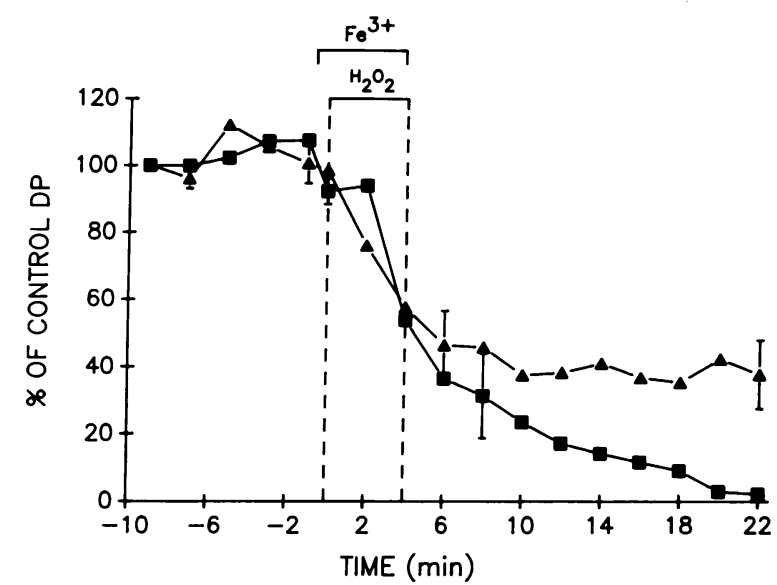

Figure 8. Similarity of normalized changes in developed pressure in hearts with and without cytoplasmic $\mathrm{Ca}^{2+}$ indicator. Pooled data from hearts loaded with 5F-BAPTA ( $\Delta$ ) and those not containing the indicator (ם) illustrating the percent change in developed pressure during the experimental protocol. There is no statistically significant difference between the two groups.

plasmic 5F-BAPTA. Before exposure to free radicals, all the hearts exhibited a normal phosphate profile, with high ATP and $\mathrm{PCr}$ concentrations, low $\mathrm{P}_{\mathrm{i}}$, and an intracellular $\mathrm{pH}$ near 7.2. By the end of the experimental protocol $\left(25 \mathrm{~min}\right.$ after $\mathrm{H}_{2} \mathrm{O}_{2}$ infusion), [ATP] had decreased by $50 \%$, and [PCr] had also fallen significantly. Thus, the changes in energy metabolites observed after free radical exposure are quite similar in the presence or absence of 5F-BAPTA, despite a slight protective effect in the presence of 5F-BAPTA.

Effect of free radicals on intracellular calcium. Does $\left[\mathrm{Ca}^{2+}\right]_{\mathrm{i}}$ increase as a consequence of free radical generation? Fig. 10 depicts representative ${ }^{19} \mathrm{~F}-\mathrm{NMR}$ spectra from one 5F-BAPTAloaded heart $(a)$ in control, $(b)$ during $\mathrm{H}_{2} \mathrm{O}_{2} / \mathrm{Fe}^{3+}$ infusion, and (c) 12-16 min after infusion. The spectra report a rise in $\left[\mathrm{Ca}^{2+}\right]_{i}$ during infusion of the $\mathrm{H}_{2} \mathrm{O}_{2} / \mathrm{Fe}^{3+}$ solution, as evidenced by the relative enhancement of the calcium-bound peak at $8 \mathrm{ppm}(b)$. The relative predominance of the calcium-bound peak is even greater 12-16 min after the infusion was terminated (c).

The results in $A$ were obtained with the usual protocol $(0.5$ $\left.\mathrm{mM}[\mathrm{Ca}]_{\mathrm{o}}, 30^{\circ} \mathrm{C}\right)$, but we ascertained whether the general findings would be similar at a more physiologic $[\mathrm{Ca}]_{\mathrm{o}}$ and temperature. Fig. $10 B$ illustrates representative ${ }^{19} \mathrm{~F}$-NMR spectra from another heart perfused with $1.0 \mathrm{mM}[\mathrm{Ca}]_{\mathrm{o}}$ at $37^{\circ} \mathrm{C}$. Spectrum $a$ was obtained during control, $b$ during infusion of free radicals, and $c$ 12-16 min after infusion. Enhancement of the calciumbound peak during and after free radical infusion is evident and comparable to that noted with $0.5 \mathrm{mM}[\mathrm{Ca}]_{o}$ at $30^{\circ} \mathrm{C}$. Fig. 11 shows pooled data for $\left[\mathrm{Ca}^{2+}\right]_{\mathrm{i}}$ from all seven hearts subjected to the standard protocol. In the control period, time-averaged $\left[\mathrm{Ca}^{2+}\right]_{\mathrm{i}}$ is quite stable with an average value of $347 \pm 14 \mathrm{nM}$. $\left[\mathrm{Ca}^{2+}\right]_{\mathrm{i}}$ begins to rise during the free radical infusion, demonstrates a transient increase to $1,026 \pm 295 \mathrm{nM}$ during the initial 4 min after the infusion, then settles to a plateau at two to three times control levels.

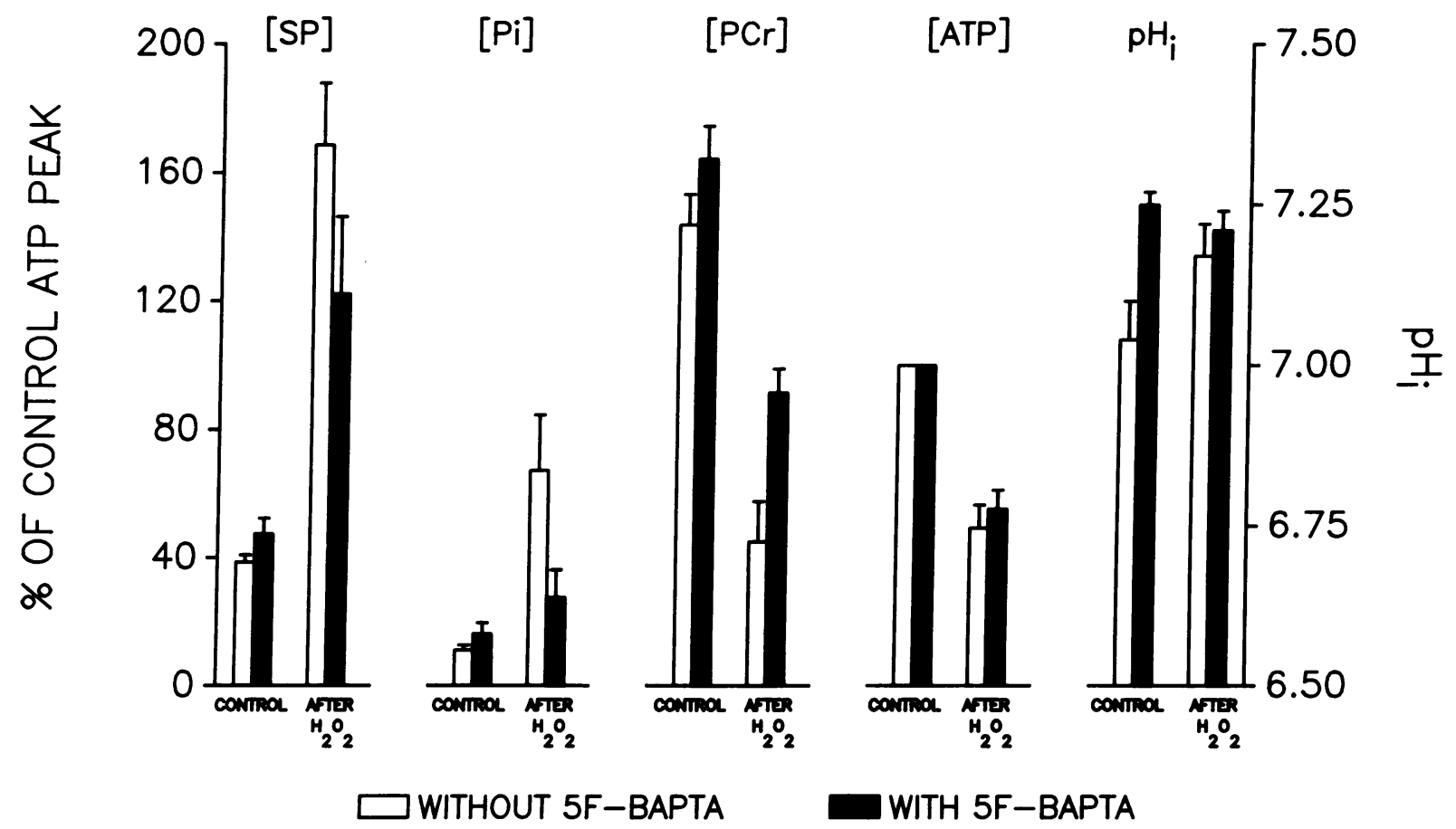

Figure 9. Metabolic changes in all hearts during control and after $\mathrm{H}_{2} \mathrm{O}_{2}$. Bar graphs depict the high energy phosphate levels ([SP], [Pi], [PCr], [ATP]), and $\mathrm{pH}_{\mathrm{i}}$ observed at the beginning and end of the experimental protocol in hearts loaded with 5F-BAPTA (solid bars) and in hearts not loaded with 5F-BAPTA (open bars). Data expressed as percent of control ATP peak in each heart. Means \pm SE. Significant differences between the two groups were noted for $[\mathrm{PCr}](P<0.05)$ and for $\mathrm{pH}_{\mathrm{i}}$ at the end of the experiment $(P<0.05)$. The data for the hearts not loaded with 5F-BAPTA are recalculated from Fig. 6. 

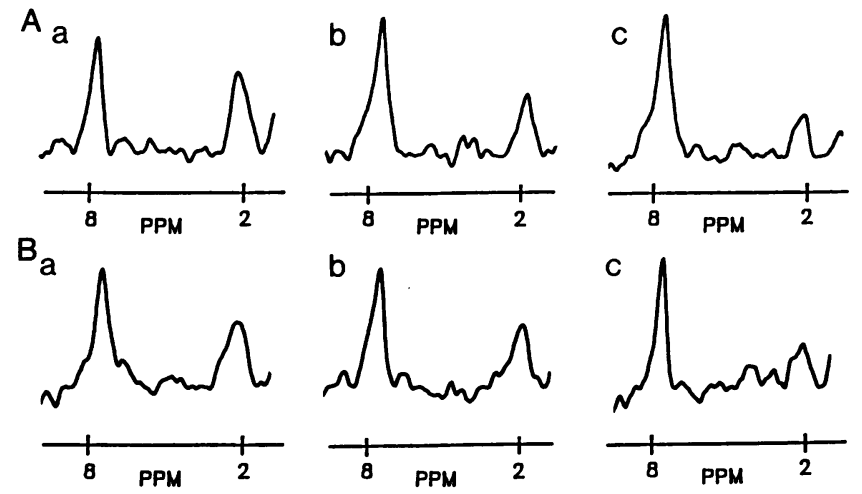

Figure 10. (A) Representative ${ }^{19} \mathrm{~F}-\mathrm{NMR}$ spectra from a heart $(0.5 \mathrm{mM}$ $[\mathrm{Ca}]_{\mathrm{o}}, 30^{\circ} \mathrm{C}$ ) during control $(a), \mathrm{H}_{2} \mathrm{O}_{2} / \mathrm{Fe}^{3+}$ infusion $(b)$, and $12-16$ min after infusion of the free radical generating system $(c)$. The peak at $8 \mathrm{ppm}$ reports the Ca-bound species, whereas the peak at $2 \mathrm{ppm}$ reflects the free indicator. $\left[\mathrm{Ca}^{2+}\right]_{\mathrm{i}}$ in nanomolar: $(a) 363,(b) 824,(c)$ 1,017. (B) Representative ${ }^{19} \mathrm{~F}-\mathrm{NMR}$ spectra from a heart exposed to $1.0 \mathrm{mM}$ [Ca] perfusate at $37^{\circ} \mathrm{C}$. (a) during control, $($ b $) \mathrm{H}_{2} \mathrm{O}_{2} / \mathrm{Fe}^{3+}$ infusion, (c) 12-16 min after infusion. $\left[\mathrm{Ca}^{2+}\right]_{\mathrm{i}}$ in $\mathrm{nM}$ using the value of $337 \mathrm{nM}$ for $K_{\mathrm{d}}$ at $37^{\circ} \mathrm{C}$ : (a) 336, (b) 646, (c) 893 .

These concentrations of intracellular free calcium are orders of magnitude lower than would be seen if cell membrane integrity were entirely disrupted, but they are certainly sufficient to activate contraction $(56,57)$. Comparison of the time course of the rise in $\left[\mathrm{Ca}^{2+}\right]_{\mathrm{i}}$ to that of the contracture in Fig. $3 B$ reveals appropriate timing for the initiation of contracture to be due to a rise in $\left[\mathrm{Ca}^{2+}\right]_{i}$. The absence of a progressive rise in $\left[\mathrm{Ca}^{2+}\right]_{\mathrm{i}}$ during washout of the free radical generating system may reflect the $\mathrm{Ca}^{2+}$ buffering effect of cytoplasmic 5FBAPTA, since the absolute diastolic pressure changes in these hearts $(11.7 \pm 2.0 \mathrm{~mm} \mathrm{Hg}$ in control, $37.5 \pm 8.2 \mathrm{~mm} \mathrm{Hg} 25 \mathrm{~min}$ after $\mathrm{H}_{2} \mathrm{O}_{2}$ infusion) were considerably more modest in magnitude than those in hearts not containing the indicator (cf. Fig. 3). It should also be noted that 5F-BAPTA provides a lower-limit estimate of the true spatio-temporal average $\left[\mathrm{Ca}^{2+}\right]_{i}(49)$. Thus, we conclude that the actual changes in $\left[\mathrm{Ca}^{2+}\right]_{\mathrm{i}}$ are at least as large as those in Fig. 11, but it seems likely that they may be considerably greater in hearts not containing the indicator.

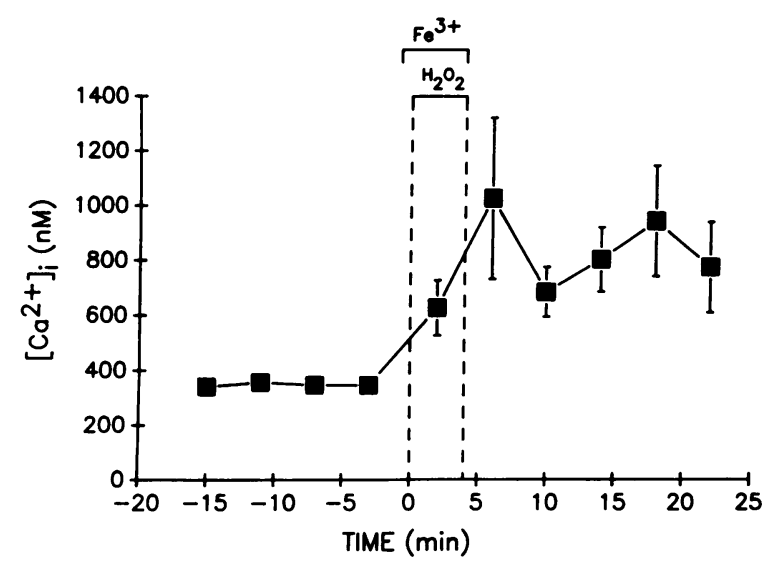

Figure 11. Pooled data from seven hearts loaded with 5F-BAPTA illustrating the mean changes $( \pm \mathrm{SE})$ in intracellular free calcium concentration during the standard experimental protocol.
Even if $\left[\mathrm{Ca}^{2+}\right]_{\mathrm{i}}$ were no higher than $600-1,000 \mathrm{nM}$, such levels may well suffice to produce myofilament activation of the magnitude observed during free radical generation. Yue et al. (57) have estimated that $\left[\mathrm{Ca}^{2+}\right]_{i}$ in this range, if distributed homogeneously in time and space, would be capable of generating $50-90 \%$ of maximal $\mathrm{Ca}^{2+}$-activated force in mammalian ventricular muscle.

\section{Discussion}

Mechanism of contracture induced by free radicals. We have observed that exogenously generated free radicals dramatically undermine myocardial function, consistent with previous observations from other laboratories $(9,10)$. The most striking mechanical change is contracture; indeed, the progressive increase in diastolic force accounts for most of the associated fall in developed pressure during twitch contractions (Fig. 3). The functional changes resemble those that have been reported upon reperfusion after 45-60 min of global ischemia in rabbit hearts $(46,58,59)$.

The development of contracture implies either critical ATP depletion or cytosolic calcium overload $(24,45)$. Although $P_{i}$ accumulation and partial PCr depletion are also observed, neither of these factors would be expected to elevate diastolic tension (35). Two lines of evidence argue against a causal role for ATP depletion in the contracture. Although ATP did fall to $\sim 50 \%$ of control levels by the end of the observation period, this magnitude of ATP depletion falls far short of that which would be required to induce rigor crossbridges (45). In addition, the time course of ATP depletion follows that of the contracture with a lag of at least 5-10 min (compare Figs. $3 B$ and 6 $A)$. In contrast, $\left[\mathrm{Ca}^{2+}\right]_{\mathrm{i}}$ rises quickly and, if anything, precedes the onset of contracture (compare Figs. $3 B$ and 11). These considerations leave little doubt that the dominant factor here is the increase in $\left[\mathrm{Ca}^{2+}\right]_{\mathrm{i}}$ rather than the fall in ATP. In this sense, the mechanism resembles that most often invoked to explain diastolic dysfunction in reperfused myocardium (26, 46), but contrasts with our own conclusions regarding the contracture that occurs during total global ischemia (45). The fact that two different mechanisms prevail in distinct settings (calcium overload in reperfusion and after free radicals, vs. ATP depletion in ischemia) serves to emphasize the importance of simultaneously measuring high energy phosphates and $\left[\mathrm{Ca}^{2+}\right]_{i}$; the development of diastolic tension in any given setting cannot itself be taken as evidence to favor one mechanism over the other.

Despite the primacy of changes in $\left[\mathrm{Ca}^{2+}\right]_{i}$ here, calcium overload and ATP depletion should be viewed as interactive rather than mutually exclusive mechanisms. Impairment of oxidative phosphorylation could, in principle, contribute to ATP depletion, but this was not a predominant effect in our system given the persistently low lactate levels during our protocol. Indeed, the alterations in calcium homeostasis can probably account for much of the observed ATP depletion $(28,60)$. Elevated $\left[\mathrm{Ca}^{2+}\right]_{\mathrm{i}}$ would activate both actomyosin ATPase and $\mathrm{Ca}^{2+}$-ATPase to favor ATP depletion, and the rundown of ion gradients that might result from ATP depletion would further perpetuate the process. Yet another exacerbating factor is the deleterious effect of high intracellular calcium on energy turnover, particularly the energetic cost exacted by calcium cycling in mitochondria (61). 
How is $\left[\mathrm{Ca}^{2+}\right]_{i}$ elevated by free radicals? We have observed that intracellular free calcium rises quickly with exposure to the $\mathrm{H}_{2} \mathrm{O}_{2} / \mathrm{Fe}^{3+}$ free radical generating system, after which $\left[\mathrm{Ca}^{2+}\right]_{\mathrm{i}}$ never returns to baseline. This free radical-mediated calcium overload is of particular interest since the concentration of radicals generated here is of the same order of magnitude as that noted in postischemic reperfusion (Fig. 2).

The irreversible rise in $\left[\mathrm{Ca}^{2+}\right]_{i}$ might result from several mechanisms. Exogenous free radicals would be expected to enhance cellular calcium loading by the known inhibition of $\mathrm{Na}^{+}$. $\mathrm{K}^{+}$ATPase in the surface membrane and of $\mathrm{Ca}^{2+}$-ATPase in both the sarcolemma and the sarcoplasmic reticulum $(20,22$, $23,62-65)$. Free radicals are also capable of injuring mitochondrial $\mathrm{Ca}^{2+}$-ATPase (34). These various effects may be direct consequences of the oxidant species, or they may be mediated through end products of lipid peroxidation which could in turn react with integral membrane proteins. Disruption of cell integrity has been argued not to be necessary $(17,34)$. In fact, our results provide direct evidence against wholesale sarcolemmal disruption by free radicals: if such disruption had occurred, the rise in $\left[\mathrm{Ca}^{2+}\right]_{i}$ would have been even greater.

We have observed a temporal correlation between the perturbation of calcium homeostasis by free radicals and the accumulation of sugar phosphates. Because a phosphomonoester peak has not been observed in other calcium overload states $(60,66)$, we have rejected the idea that calcium overload per se inhibits glycolysis (67). Instead, the available data are entirely consistent with the opposite view: glycolytic inhibition is primary, and leads to a secondary derangement in calcium homeostasis.

How might glycolytic inhibition be implicated in the rise in $\left[\mathrm{Ca}^{2+}\right]_{\mathrm{i}}$ ? Several lines of evidence support the notion that glycolytically derived ATP is particularly important for the maintenance of ion gradients across the sarcolemma, whereas oxidatively derived ATP preferentially supports contractile function $(9,17,24,68)$. During ischemia, it has been proposed that glucose produces ATP in proximity to the sarcolemma at a critical rate to maintain calcium homeostasis, thus delaying calcium overload (24). Results of Jeremy et al. (49) emphasize the importance of glycolysis in maintaining calcium homeostasis in postischemic rabbit myocardium. Although $0.1 \mathrm{mM}$ iodoacetate, an inhibitor of glycolysis, had no effect on function or high energy phosphates before ischemia, application of this agent upon reperfusion caused a marked contracture and prevented the usual return of $\left[\mathrm{Ca}^{2+}\right]_{i}$ to basal levels in the postischemic period. Taken together, the various lines of evidence suggest that glycolysis is particularly important in maintaining cation gradients across the surface membrane. Thus, it seems entirely plausible that the observed inhibition of glycolysis might suffice to produce the elevation of $\left[\mathrm{Ca}^{2+}\right]_{\mathrm{i}}$, which in turn would initiate the functional deterioration. Consistent with this hypothesis, primary glycolytic inhibition (by iodoacetate or 2deoxy-glucose) mimics many of the functional and metabolic effects of free radicals (68). These results give reason to wonder whether the ill consequences of exogenous free radicals might be blunted by maneuvers (e.g., glucose and insulin) designed to preserve or enhance glycolysis.

Implications for reperfusion injury. Our observation that free radicals elevate intracellular $\left[\mathrm{Ca}^{2+}\right]$ lends new support to the idea that calcium mediates many of the deleterious effects of free radicals elaborated upon reperfusion (1-8). Indeed, direct measurements of $\left[\mathrm{Ca}^{2+}\right]_{i}$ reveal an elevation of $\left[\mathrm{Ca}^{2+}\right]_{\mathrm{i}}$ in the early postischemic period (33), coincident with the period of greatest free radical elaboration $(2,3,30)$. It is worth testing whether maneuvers that attenuate myocardial stunning by acting on free radicals $(5-8)$ also prevent the increase in $\left[\mathrm{Ca}^{2+}\right]_{\mathrm{i}}$. Nevertheless, there are important differences in the behavior of $\left[\mathrm{Ca}^{2+}\right]_{\mathrm{i}}$ during reperfusion and during exogenous free radical generation. After brief (15-20 min) periods of ischemia, timeaveraged $\left[\mathrm{Ca}^{2+}\right]_{\mathrm{i}}$ remains elevated only briefly before returning to basal levels (33). Such recovery was absent after $4 \mathrm{~min}$ of exogenous radical generation (Fig. 11). The present results also indicate a long-lasting derangement of energy metabolism with $\mathrm{H}_{2} \mathrm{O}_{2}$ and $\mathrm{Fe}^{3+}$, unlike the rapid recovery that is the rule in reperfusion after brief ischemic periods (69). As a possible origin of the discrepancies, it should be noted that radical generation occurs as a short-lived burst upon reperfusion $(2,3,30)$, but is sustained for $4 \mathrm{~min}$ with the experimental protocol used here. Although the peak concentrations of $\cdot \mathrm{OH}$ are similar (Fig. 2), the total amount of radical elaboration is much greater here than in the stunned myocardium. It is also possible that the site of radical generation is different in the two settings. Thus, caution is merited in extrapolating the findings with $\mathrm{H}_{2} \mathrm{O}_{2}$ and $\mathrm{Fe}^{3+}$ to the complex biology of myocardial reperfusion.

\section{Acknowledgments}

We thank Robert G. Weiss and Lewis C. Becker for helpful discussions, and Robert G. Weiss and Koenraad Vandegaer for assistance with preparation of cytoplasmic extracts.

This study was supported by grants R01 HL-44065, K04 HL01872, R29 HL-38324, and P50 HL-17655 from the National Institutes of Health.

\section{References}

1. Zweier, J. L. 1988. Measurement of superoxide-derived free radicals in the reperfused heart: evidence for a free radical mechanism of reperfusion injury. $J$. Biol. Chem. 263:1353-1357.

2. Zweier, J. L., J. T. Flaherty, and M. L. Weisfeldt. 1987. Direct measurement of free radical generation following reperfusion of ischemic myocardium Proc. Natl. Acad. Sci. USA. 84:1404-1407.

3. Bolli, R., B. S. Patel, M. O. Jeroudi, E. K. Lai, and P. B. McCay. 1988. Demonstration of free radical generation in "stunned" myocardium of intact dogs with the use of the spin trap-phenyl $N$-tert-butyl nitrone. J. Clin. Invest. 82:476-485.

4. McCord, J. M. 1985. Oxygen derived free radicals in postischemic tissue injury. N. Engl. J. Med. 312:159-163.

5. Bolli, R., W.-X. Zhu, C. J. Hartley, L. H. Michael, J. E. Repine, M. L. Hess, R. C. Kukreja, and R. Roberts. 1987. Attenuation of dysfunction in the post-ischemic "stunned" myocardium by dimethylthiourea. Circulation. 76:458-568.

6. Ambrosio, G., M. L. Weisfeldt, W. E. Jacobus, and J. T. Flaherty, 1987. Evidence for a reversible oxygen radical-mediated component of reperfusion injury: reduction by recombinant human superoxide dismutase administered at the time of reflow. Circulation. 75:282-291.

7. Jolly, S. R., W. J. Kane, M. B. Bailie, G. D. Abrams, and B. R. Lucchesi. 1984. Canine myocardial reperfusion injury: its reduction by the combined administration of superoxide dismutase and catalase. Circ. Res. 54:277-285.

8. Burton, K. P. 1985. Superoxide dismutase enhances recovery following myocardial ischemia. Am. J. Physiol. 248:H637-H643.

9. Goldhaber, J. I., S. Ji, S. T. Lamp, and J. N. Weiss. 1989. Effects of exogenous free radicals on electromechanical function and metabolism in isolated 
rabbit and guinea pig ventricle: implications for ischemia and reperfusion injury. J. Clin. Invest. 83:1800-1809.

10. Burton, K. P., J. M. McCord, and G. Ghai. 1984. Myocardial alterations due to free-radical generation. Am. J. Physiol. 246:H776-H783.

11. Asinger, R. W., D. A. Petersen, K. J. Elsperger, and D. Homans. 1988 Long-term recovery of $\mathrm{LV}$ wall thickening after one hour of ischemia is not affected when superoxide dismutase and catalase are administered during the 1st 45 minutes of reperfusion. J. Am. Coll. Cardiol. 11:163A. (Abstr.)

12. Reimer, K. A., and R. B. Jennings. 1985. Failure of the xanthine oxidase inhibitor allopurinol to limit infarct size after ischemia and reperfusion in dogs. Circulation. 71:1069-1075.

13. Uraizee, A., K. A. Reimer, C. E. Murray, and R. B. Jennings. 1987. Failure of superoxide dismutase to limit size of myocardial infarction after 10 minutes of ischemia and 4 days of reperfusion in dogs. Circulation. 75:12371248.

14. Tarr, M., and D. P. Valenzeno. 1989. Modification of cardiac action potential by photosensitizer-generated reactive oxygen. J. Mol. Cell. Cardiol. 21:539-543.

15. Barrington, P. L., C. F. Meier, Jr., and W. B. Weglicki. 1988. Abnorma electrical activity induced by free radical generating systems in isolated cardiocytes. J. Mol. Cell. Cardiol. 20:1163-1178.

16. Matsuura, H., and M. J. Shattock. 1991. Membrane potential fluctuation and transient inward currents induced by reactive oxygen intermediates in isolated rabbit ventricular cells. Circ. Res. 68:319-329.

17. Weiss, J. N., and S. T. Lamp. 1989. Cardiac ATP-sensitive $\mathrm{K}^{+}$channels Evidence for preferential regulation by glycolysis. J. Gen. Physiol. 94:911-935.

18. Hyslop, P. A., D. B. Hinshaw, W. A. Halsey, Jr., I. U. Schraufstatter, R. D. Sauerheber, R. G. Spragg, J. H. Jackson, and C. G. Cochrane. 1988. Mechanisms of oxidant-mediated cell injury: the glycolytic and mitochondrial pathways of ADP phosphorylation are major intracellular targets inactivated by hydrogen peroxide. J. Biol. Chem. 263:1665-1675.

19. Chatham, J., H. F. Gilbert, and G. K. Radda. 1989. The metabolic consequences of hydroperoxide perfusion on the isolated rat heart. Eur. J. Biochem. 184:657-662.

20. Hess, M. L., N. H. Manson, and E. Okabe. 1982. Involvement of free radicals in the pathophysiology of ischemic heart disease. Can. J. Physiol. Pharmacol. 60:1382-1389.

21. Okabe, E., R. Fujimaki, M. Masahiro, and H. Ito. 1989. Possible mechanism responsible for mechanical dysfunction of ischemic myocardium: A role of oxygen free radicals. Jpn. Circ. J. 53:1132-1137.

22. Kim, M. S., and T. Akera. 1987. $\cdot \mathrm{O}_{2}^{-}$free radicals: cause of ischemia-reperfusion injury to cardiac $\mathrm{Na}^{+}-\mathrm{K}^{+}$ATPase. Am. J. Physiol. 252:H252-H257.

23. Shattock, M. J., H. Matsuura, and D. J. Hearse. 1991. Effects of oxidan stress on calcium inward current and sodium pump current in isolated ventricular myocytes. Biophys. J. 59:559a. (Abstr.)

24. Owen, P., S. Dennis, and L. H. Opie. 1990. Glucose flux rate regulates onset of ischemic contracture in globally underperfused rat hearts. Circ. Res. 66:344-354.

25. Wier, W. G., and P. Hess. 1984. Excitation-contraction coupling in cardiac Purkinje fibers: effects of cardiotonic steroids on the intracellular $\left[\mathrm{Ca}^{2+}\right]$ transient, membrane potential, and contraction. J. Gen. Physiol. 83:395-415.

26. Kitakaze, M., H. F. Weisman, and E. Marban. 1988. Contractile dysfunction and ATP depletion after transient calcium overload in perfused ferret hearts. Circulation. 77:685-695.

27. Kitakaze, M., and E. Marban. 1989. Cellular mechanism of the modulation of contractile function by coronary perfusion pressure in ferret hearts. Physiol. (Lond.). 414:455-472.

28. Marban, E., Y. Koretsune, M. Corretti, V. P. Chacko, and H. Kusuoka 1989. Calcium and its role in myocardial cell injury during ischemia and reperfusion. Circulation. 80:IV-17-IV-22.

29. Thompson, J. A., and M. L. Hess. 1986. The oxygen free radical system: A fundamental mechanism in the production of myocardial necrosis. Prog. Cardio vasc. Dis. 28:449-462.

30. Zweier, J. L., P. Kuppusamy, R. Williams, B. K. Rayburn, D. Smith M. L. Weisfeldt, and J. T. Flaherty. 1989. Measurements and characterization of postischemic free radical generation in the isolated perfused heart. J. Biol. Chem. 264:18890-18895.

31. Smith, G. A., R. T. Hesketh, J. C. Metcalfe, J. Feeney, and P. G. Morris. 1983. Intracellular calcium measurements by ${ }^{19} \mathrm{~F}$ NMR of fluorine-labelled chelators. Proc. Natl. Acad. Sci. USA. 80:7178-7182.

32. Marban, E., M. Kitakaze, H. Kusuoka, J. K. Porterfield, D. T. Yue, and V. P. Chacko. 1987. Intracellular free calcium concentration measured with ${ }^{19} \mathrm{~F}$ NMR spectroscopy in intact ferret hearts. Proc. Natl. Acad. Sci. USA. 84:60056009.

33. Marban, E., M. Kitakaze, Y. Koretsune, D. T. Yue, V. P. Chacko, and M. M. Pike. 1990. Quantification of $\left[\mathrm{Ca}^{2+}\right]_{i}$ in perfused hearts: critical evaluation of 5F-BAPTA and nuclear magnetic resonance method as applied to the study of ischemia and reperfusion. Circ. Res. 66:1255-1267.
34. Harris, E. J., R. Booth, and M. B. Cooper. 1982. The effect of superoxide generation on the ability of mitochondria to take up and retain $\mathrm{Ca}^{2+}$. FEBS (Fed. Eur. Biochem. Soc.) Lett. 146:267-272.

35. Kusuoka, H., M. L. Weisfeldt, W. E. Jacobus, J. Zweier, and E. Marban 1986. Mechanism of early contractile failure during hypoxia in intact ferret heart: evidence for modulation of maximal $\mathrm{Ca}^{2+}$-activated force by inorganic phosphate. Circ. Res. 59:270-282.

36. Allen, D. G., P. G. Morris, C. H. Orchard, and J. S. Pirolo. 1985. A nuclear magnetic resonance study of metabolism in the ferret heart during hypoxia and inhibition of glycolysis. J. Physiol. (Lond.). 361:185-204.

37. Gadian, D. G., G. K. Radda, R. E. Richards, and P. J. Seely. 1979. ${ }^{31}$ P NMR in living tissue: the road from a promising to an important tool in biology. In Biological Applications of Magnetic Resonance. R. G. Shulman, editor. Academic Press, Inc., New York. 463-535.

38. Navon, G., R. Navon, R. G. Shulman, and T. Yamane. 1978. Phosphate metabolites in lymphoid, Friend erythroleukemia, and HeLa cells observed by high-resolution ${ }^{31} \mathrm{P}$ nuclear magnetic resonance. Proc. Natl. Acad. Sci. USA. 75:891-895.

39. Ugurbil, K., R. G. Shulman, and T. R. Brown. 1979. High-resolution ${ }^{31} \mathrm{P}$ and ${ }^{13} \mathrm{C}$ nuclear magnetic resonance studies of Escherichia coli cells in vivo. In Biological Applications of Magnetic Resonance. R. G. Shulman, editor. Academic Press, New York. 537-589.

40. Gyulai, L., L. Bolinger, J. S. Leigh, Jr., C. Barlow, and B. Chance. 1984 Phosphorylethanolamine-the major constituent of the phosphomonester peak observed by ${ }^{31}$ P-NMR on developing dog brain. FEBS (Fed. Eur. Biochem. Soc.) Lett. 178:137-142.

41. Kuppusamy, P., and J. L. Zweier. 1989. Characterization of free radical generation by xanthine oxidase: evidence for hydroxyl radical generation. J. Biol. Chem. 264:9880-9884.

42. Thompson-Gorman, S. L., and J. L. Zweier. 1990. Evaluation of the role of xanthine oxidase in myocardial reperfusion injury. J. Biol. Chem. 265:66566663.

43. Snedecor, G. W., and W. G. Cochran. 1989. Statistical Methods. 8th edition. Iowa State University Press, Ames, IA. 503 pp.

44. Buettner, G. R. 1987. Spin trapping: ESR parameters of spin adducts. Free Radical Biol. Med. 3:259-303.

45. Koretsune, Y., and E. Marban. 1989. Mechanism of ischemic contracture in ferret hearts: relative roles of $\left[\mathrm{Ca}^{2+}\right]_{\mathrm{i}}$ elevation and ATP depletion. Am. J. Physiol. 258:H9-H16.

46. Shine, K. I., and A. M. Douglas. 1983. Low calcium reperfusion of ischemic myocardium. J. Mol. Cell. Cardiol. 15:251-260.

47. Burton, K. P., A. C. Morris, K. D. Massey, L. M. Buja, and H. K. Hagler. 1988. Alterations in ionic calcium transients in cultured neonatal rat myocytes induced by exposure to free radicals can be modified by alpha-tocopherol. Circulation. 78:II-215. (Abstr.)

48. Josephson, R. A., H. S. Silverman, E. G. Lakatta, M. D. Stern, and J. L. Zweier. 1991. Study of the mechanisms of hydrogen peroxide and hydroxyl free radical induced cellular injury and calcium overload in cardiac myocytes. J. Biol. Chem. 266:2354-2361.

49. Jeremy, R., R. Lewis, and L. Becker. 1989. Relation of glycolysis and calcium during reflow to function of stunned myocardium. Circulation. 80:II235. (Abstr.)

50. Chatham, J., H. F. Gilbert, and G. K. Radda. 1988. Inhibition of glucose phosphorylation by fatty acids in the perfused rat heart. FEBS (Fed. Eur. Biochem. Soc.) Lett. 238:445-449.

51. Evans, F. E., and N. O. Kaplan. 1977. ${ }^{31} \mathrm{P}$ Nuclear magnetic resonance studies of HeLa cells. Proc. Natl. Acad. Sci. USA. 74:4909-4913.

52. Prioetti, E., G. Carpinelli, M. DiVito, F. Belardelli, I. Gresser, and F. Podo. 1986. ${ }^{31} \mathrm{P}$ Nuclear magnetic resonance analysis of interferon-induced alterations of phospholipid metabolites in interferon-sensitive and interferon-resistan Friend leukemia cell turnover in mice. Cancer Res. 46:2849-2857.

53. Evanochko, W. T., T. T. Sakai, T. C. Ng, N. R. Krishna, H. D. Kim, R. B. Ziedler, V. K. Ghanta, R. W. Brockman, L. M. Schiffer, P. G. Braunschweiger, et al. 1984. NMR Study of in vivo RIF-1 tumors: analysis of perchloric acid extracts and identification of ${ }^{1} \mathrm{H},{ }^{31} \mathrm{P}$ and ${ }^{13} \mathrm{C}$ Resonances. Biochim. Biophys. Acta. 805:104-116.

54. Steenbergen, C., E. Murphy, L. Levy, and R. E. London. 1987. Elevation in cytosolic free calcium concentration early in myocardial ischemia in perfused rat heart. Circ. Res. 60:700-707.

55. Scharfman, H. E, and P. A. Schwartzkroin. 1989. Protection of dentate hilar cells from prolonged stimulation by intracellular calcium chelation. Science (Wash. DC). 246:257-260.

56. Fabiato, A. 1981. Myoplasmic free calcium concentration reached during the twitch of an intact isolated cardiac cell and during calcium-induced release of calcium from the sarcoplasmic reticulum of a skinned cardiac cell from the adult rat or rabbit ventricle. J. Gen. Physiol. 78:457-497.

57. Yue, D. T., E. Marban, and W. G. Wier. 1986. Relationship between force 
and intracellular $\left[\mathrm{Ca}^{2+}\right]$ in tetanized mammalian heart muscle. J. Gen. Physiol. 87:223-242.

58. Bourdillon, P. D. V., and P. A. Poole-Wilson. 1981. Effects of ischaemia and reperfusion on calcium exchange and mechanical function in isolated rabbit myocardium. Cardiovasc. Res. 15:121-130.

59. Ferrari, R., A. Albertini, S. Curello, C. Ceconi, F. DiLisa, R. Raddino, and O. Visioli. 1986. Myocardial recovery during post-ischaemic reperfusion: effects of nifedipine, calcium and magnesium. J. Mol. Cell. Cardiol. 18:487-498.

60. Kusuoka, H., W. E. Jacobus, and E. Marban. 1988. Calcium oscillation in digitalis-induced ventricular fibrillation: Pathogenetic role and metabolic consequences in isolated ferret hearts. Circ. Res. 62:609-619.

61. Lehninger, A. L. 1970. Mitochondria and calcium ion transport. Biochem. J. 119:129-138.

62. Jackson, C. V., J. K. Mickelson, T. K. Pope, P. S. Rao, and B. R. Lucchesi 1986. $\mathrm{O}_{2}$ free radical-mediated myocardial and vascular dysfunction. Am. J. Physiol. 251:H1225-H1231.

63. Kaneko, M., R. E. Beamish, and N. Dhalla. 1989. Depression of heart sarcolemmal $\mathrm{Ca}^{2+}$-pump activity by oxygen free radicals. Am. J. Physiol. 256:H368-H374.
64. Rowe, G. T., N. H. Manson, M. Caplan, and M. L. Hess. 1983. Hydrogen peroxide and hydroxyl radical mediation of activated leukocyte depression of cardiac sarcoplasmic reticulum. Circ. Res. 53:584-591.

65. Hess, M. L., E. Okabe, and H. A. Kontos. 1981. Proton and free oxygen radical interaction with the calcium transport system of cardiac sarcoplasmic reticulum. J. Mol. Cell. Cardiol. 13:767-772.

66. Renlund D. G., E. G. Lakatta, E. D. Mellits, and G. Gerstenblith. 1985. Calcium-dependent enhancement of myocardial diastolic tone and energy utilization dissociates systolic work and oxygen consumption during low sodium perfusion. Circ. Res. 57:876-888.

67. Auffermann, W., S. Wagner, S. Wu, P. Buser, W. W. Parmley, and J. Wikman-Coffert. 1990. Calcium inhibition of glycolysis contributes to ischemic injury. Cardiovasc. Res. 24:510-520.

68. Weiss, J. N., and B. Hiltbrand. 1985. Functional compartmentation of glycolytic vs. oxidative metabolism in isolated rabbit heart. J. Clin. Invest. 75:436-447.

69. Becker, L. C., and G. Ambrosio. 1987. Myocardial consequences of reperfusion. Prog. Cardiovasc. Dis. 30:23-44. 